\title{
Human RecQL4 as a Novel Molecular Target for Cancer Therapy
}

\author{
Adayabalam S. Balajee \\ Cytogenetic Biodosimetry Laboratory, Radiation Emergency Assistance Center/Training Site, Oak Ridge Institute for \\ Science and Education, Oak Ridge Associated Universities, Oak Ridge, TN, USA
}

\section{Keywords}

Human RecQ helicases · Premature aging syndromes · DNA repair pathways · Chromosomal instability · Cancer · Cancer therapeutics

\begin{abstract}
Human RecQ helicases play diverse roles in the maintenance of genomic stability. Inactivating mutations in 3 of the 5 human RecQ helicases are responsible for the pathogenesis of Werner syndrome (WS), Bloom syndrome (BS), RothmundThomson syndrome (RTS), RAPADILINO, and Baller-Gerold syndrome (BGS). WS, BS, and RTS patients are at increased risk for developing many age-associated diseases including cancer. Mutations in RecQL1 and RecQL5 have not yet been associated with any human diseases so far. In terms of disease outcome, RecQL4 deserves special attention because mutations in RecQL4 result in 3 autosomal recessive syndromes (RTS type II, RAPADILINO, and BGS). RecQL4, like other human RecQ helicases, has been demonstrated to play a crucial role in the maintenance of genomic stability through participation in diverse DNA metabolic activities. Increased incidence of osteosarcoma in RecQL4-mutated RTS patients and elevated expression of RecQL4 in sporadic cancers in-
\end{abstract} expression is linked with cancer susceptibility. In this review, current and future perspectives are discussed on the potential use of RecQL4 as a novel cancer therapeutic target.

(c) 2021 S. Karger AG, Basel

\section{Introduction}

Helicases are specialized enzymes that unwind DNADNA or RNA-DNA duplexes, and the duplex unwinding is critical for many vital cellular processes such as DNA replication, transcription, recombination, and repair [Brosh and Matson, 2020]. Helicases utilize the energy from ATP hydrolysis to unwind the DNA-DNA or RNADNA duplex. Helicases belonging to superfamily II are involved in many aspects of RNA and DNA metabolism, and superfamily II has 10 different families of helicases including Escherichia coli RecQ, Saccharomyces cerevisiae Sgs1, Schizosaccharomyces pombe Rqh1/Rad12, and additional RecQ-like helicase homologs that have been identified and characterized in other eukaryotes [Byrd and Raney, 2012]. Up to date, 5 human RecQ helicases with strong sequence homology to $E$. coli RecQ have been

Correspondence to:

Adayabalam Sambasivan Balajee, adayabalam.balajee@orau.org 


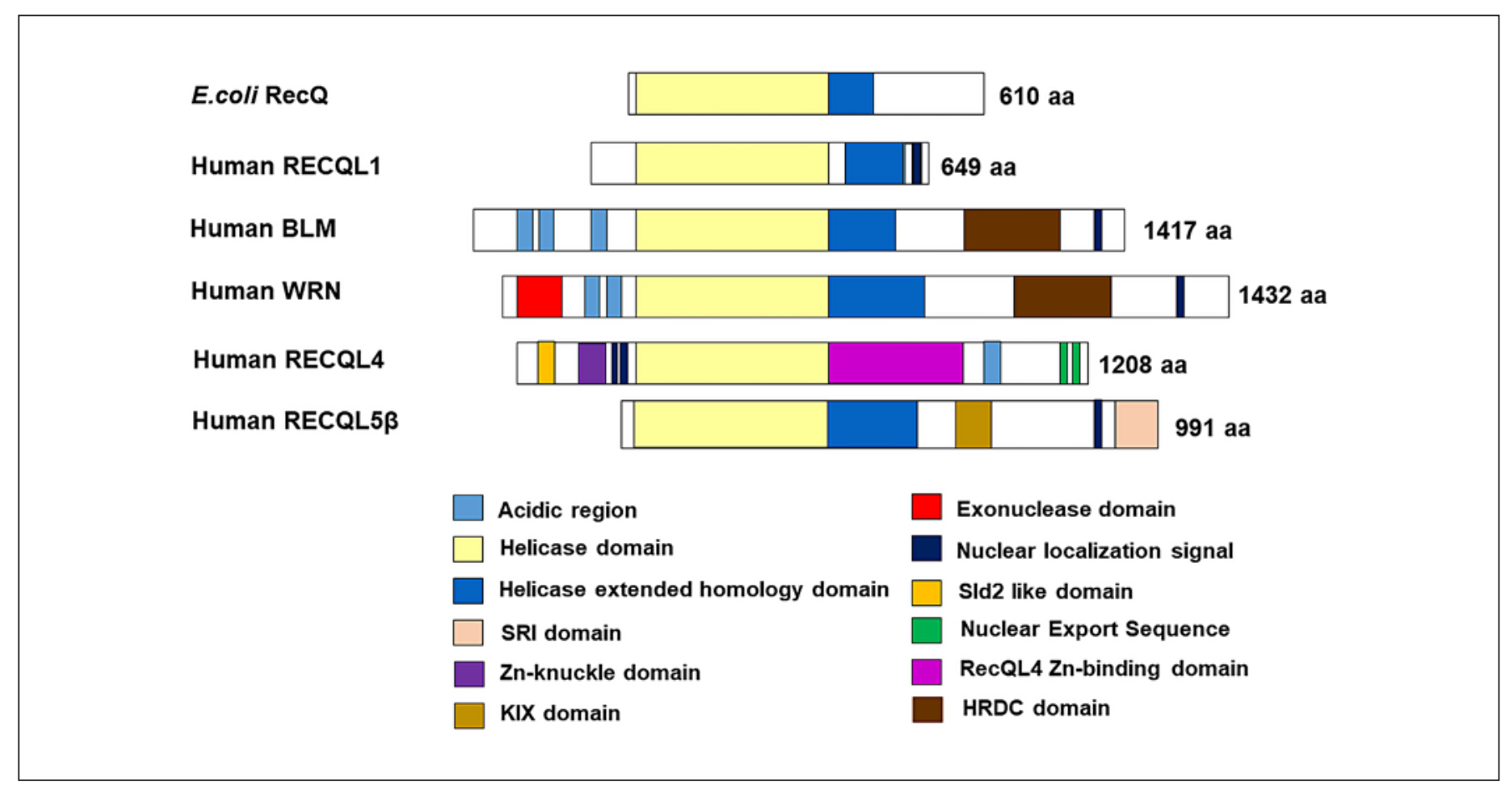

Fig. 1. Schematic diagram showing different conserved and functional domains of RecQ helicases. The conserved central helicase domain is shown in yellow. Human WRN and RecQ5 helicases are characterized by an exonuclease domain while RecQL4 is distingusihed from other human RecQ helicases in the possession of an Sld2-like domain at the N-terminal domain. The Sld2-like domain is important for initiation of DNA replication in eukaryotes. Un- like other human RecQ helicases, RecQL4 has 2 nuclear localization signals at the $\mathrm{N}$-terminal domain. HRDC domains are present only in WRN and BLM helicases. RecQL5 $\beta$ is the only helicase that has KIX and SRI domains at the C-terminal region. RecQL4 has 2 nuclear export signals at the C-terminal region for its cytoplasmic recruitment. Note that the sizes of different functional domains depicted are arbitrary. cloned [Puranam and Blackshear, 1994; Ellis et al., 1995; Yu et al., 1996; Kitao et al., 1998] and biochemically characterized [Brosh and Bohr, 2007; Bohr, 2008; Larsen and Hickson, 2013; Croteau et al., 2014]. All the RecQ-like human proteins (RecQL1, RecQL2, RecQL3, RecQL4, and RecQL5) have an amino terminal (N-terminal) domain, a helicase domain, and a carboxyl terminal (C-terminal) domain. The RecQ helicase domain is highly conserved through evolution from E. coli to eukaryotes and mediates the DNA unwinding in a $3^{\prime}$ to $5^{\prime}$ direction. The $\mathrm{N}$-terminal and C-terminal domains have unique features that distinguish the human RecQ helicases from each other. Different conserved and functional domains of human RecQ helicases are schematically represented in Figure 1, and some of the biochemical properties of the 5 human RecQ helicases are summarized in Table 1.

The exonuclease domain is found only in RecQL2 and RecQL5 helicases at the amino and carboxyl terminals, respectively. RecQL4 has 2 nuclear localization signals at the amino terminal region while other RecQ helicases have only one nuclear localization signal at the C-terminal region. Also, RecQL4 is distinctly different from other human RecQ helicases by having the Sld2-like domain at the N-terminus [Marino et al., 2013], and the Sld2 domain is a crucial DNA replication initiation factor in yeast, Drosophila, and Xenopus model systems. Additionally, RecQL4 has 2 nuclear export signals at the C-terminal region that are implicated in the cytoplasmic location of RecQL4 [Chi et al., 2012]. Helicase- and RNaseD-likeC-terminal domain (HRDC) is found only in RecQL2 and RecQL3 helicases. Kinase inducible domain (KIX) and small 3-helix domain (SRI) are present only in RecQL5. Sekelsky et al. [1999] reported that RecQL5 of Drosophila and humans exists in 3 different isoforms due to alternative splicing of mRNA of the RECQL5 gene with 19 exons. RecQLa (410 amino acids) and RecQL $\gamma$ (435 amino acids) isoforms are smaller than RecQL5 $\beta$ isoform (991 amino acids). RecQL5 $\beta$ is localized in the nucleus while RecQLa and RecQL5 $\gamma$ are localized in the cytoplasm [Shimamoto et al., 2000]. All the human RecQ he- 
Table 1. Biochemical properties of human RecQL proteins

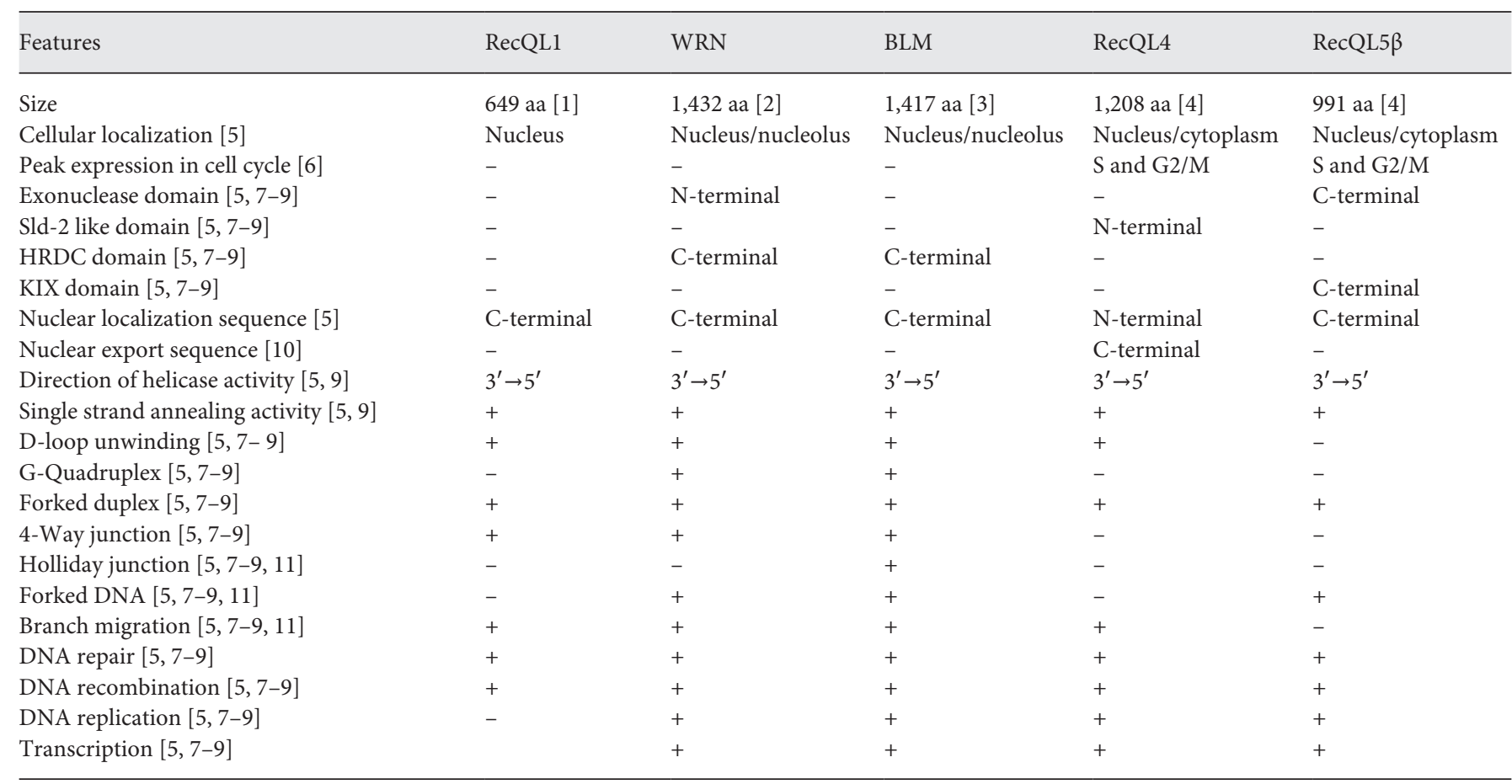

Data obtained from the following references: [1] Puranam and Blackshear, 1995; [2] Yu et al., 1996; [3] Ellis et al., 1995; [4] Kitao et al., 1998; [5] Croteau et al., 2014; [6] Kawabe et al., 2000; [7] Brosh and Bohr, 2007; [8] Bohr, 2008; [9] Larsen and Hickson, 2013; [10] Chi et al., 2012; [11] Jain et al., 2020.

licases exhibit DNA single strand annealing activity [Croteau et al., 2014]. The preferred DNA substrate specificities for unwinding by the human RecQ helicases as well as their involvement in major biological pathways are shown in Table 1. Using recombinant proteins, Kawabe et al. [2000] estimated the copy number of each of the RecQ helicases in resting human B cells: 2,100 copies per cell for RecQL1, 1,200 copies per cell for WRN, 330 copies per cell for BLM, 120 copies per cell for RecQL4 and 340 copies per cell for RecQL5 $\beta$. Interestingly, the copy number for RecQL5 $\beta$ remained unchanged in both normal and EBV-transformed B-lymphoblastoid cell lines while other RecQ helicases showed a substantial elevation in copy number after immortalization.

The biochemical and molecular functions mediated by different domains of human RecQ helicases are illustrated in Figure 2. Autosomal recessive mutations in RECQL2/WRN and RECQL3/BLM genes give rise to Werner syndrome (WS) and Bloom syndrome (BS) respectively, while RECQL4 gene mutations result in 3 autosomal recessive diseases: Rothmund-Thomson syndrome (RTS), Baller-Gerold syndrome (BGS), and RAPADILINO syndrome. RECQL2 and RecQL3 helicases are often referred as Werner and Bloom helicases because of their association with WS and BS. The clinical and cellular features of WS, BS, RTS, BGS, and RAPADILINO patients are summarized in Table 2. Additional information on the clinical features of WS, BS, and RTS can be found in the literature [Lindor et al., 1996, 2000; Larizza et al., 2010; Cunniff et al., 2017; Oshima et al., 2017]. Accelerated aging features are most pronounced in patients with WS followed by BS and RTS. Short stature is a common feature for all the human RecQ syndromes. The WS patients are characterized by skin abnormalities, osteoporosis, bilateral cataracts, and atherosclerosis, while BS patients often display erythema, type II diabetes, male infertility, and telangiectasia. In general, all the 3 RecQL4 deficient syndromes are characterized by skeletal/bone abnormalities. Features of craniosynostosis, oligodactyly, and brachyturricephaly are common in BGS patients. The term RAPADILINO refers to some of the pathological features: RAdial ray defect, PAtellar aplasia/cleft PAlate, DIarrhea/DIslocated joints, LIttle stature and NOrmal intelligence/slender NOse. Among the 5 helicases, mutations in RecQL1 and RecQL5 have not been associated with any human disorders. Cells derived from 
Table 2. Clinical and cellular features of human RecQL-deficient syndromes

\begin{tabular}{|c|c|c|c|c|c|}
\hline Clinical [1-4] & $\begin{array}{l}\text { Short stature } \\
\text { Skin abnormalities } \\
\text { Osteoporosis } \\
\text { Bilateral cataracts } \\
\text { Atherosclerosis }\end{array}$ & $\begin{array}{l}\text { Short stature } \\
\text { Erythema } \\
\text { Type II diabetes } \\
\text { Male infertility } \\
\text { Telangiectasia }\end{array}$ & $\begin{array}{l}\text { Short stature } \\
\text { Photosensitivity } \\
\text { Poikiloderma } \\
\text { Bone deformities } \\
\text { Telangiectasia }\end{array}$ & $\begin{array}{l}\text { Retarded growth } \\
\text { Craniosynostosis } \\
\text { Oligodactyly } \\
\text { Normal intelligence } \\
\text { Brachyturricephaly }\end{array}$ & $\begin{array}{l}\text { Radial ray } \\
\text { malformations } \\
\text { Abnormal palate/ } \\
\text { patella } \\
\text { Dislocated joints } \\
\text { Normal intelligence } \\
\text { Limb abnormalities }\end{array}$ \\
\hline Responsible gene & $W R N$ & $B L M$ & RECQL4 & RECQL4 & RECQL4 \\
\hline Mutations & Recessive & Recessive & Recessive & Recessive & Recessive \\
\hline Deficiency & Homozygous & Homozygous & Homozygous & Homozygous & Homozygous \\
\hline Chromosome site & $8 \mathrm{p} 11.2$ & $15 q 26.1$ & $8 \mathrm{q} 24.3$ & $8 \mathrm{q} 24.3$ & $8 \mathrm{q} 24.3$ \\
\hline Cancer type [9] & $\begin{array}{l}\text { Sarcomas } \\
\text { Meningiomas } \\
\text { Skin cancer } \\
\text { Thyroid carcinoma }\end{array}$ & $\begin{array}{l}\text { Leukemia } \\
\text { Lymphoma } \\
\text { Carcinoma }\end{array}$ & $\begin{array}{l}\text { Skin cancer } \\
\text { Osteosarcoma }\end{array}$ & $\begin{array}{l}\text { Lymphoma } \\
\text { Leukemia }\end{array}$ & $\begin{array}{l}\text { Osteosarcoma } \\
\text { Lymphoma }\end{array}$ \\
\hline
\end{tabular}

Data obtained from the following references: [1] Oshima et al., 2017; [2] Cunniff et al., 2017; [3] Larizza et al., 2010; [4] Lindor et al., 2000; [5] Salk et al., 1981; [6] Chaganti et al., 1974; [7] Ying et al., 1990; [8] Huson et al., 1990; [9] Mojumdar, 2020.

Fig. 2. A schematic diagram showing the biochemical activities for $\mathrm{N}$-terminal, core helicase, and C-terminal domains of human RecQ helicases. Adopted and modified from Killoran and Keck [2006].

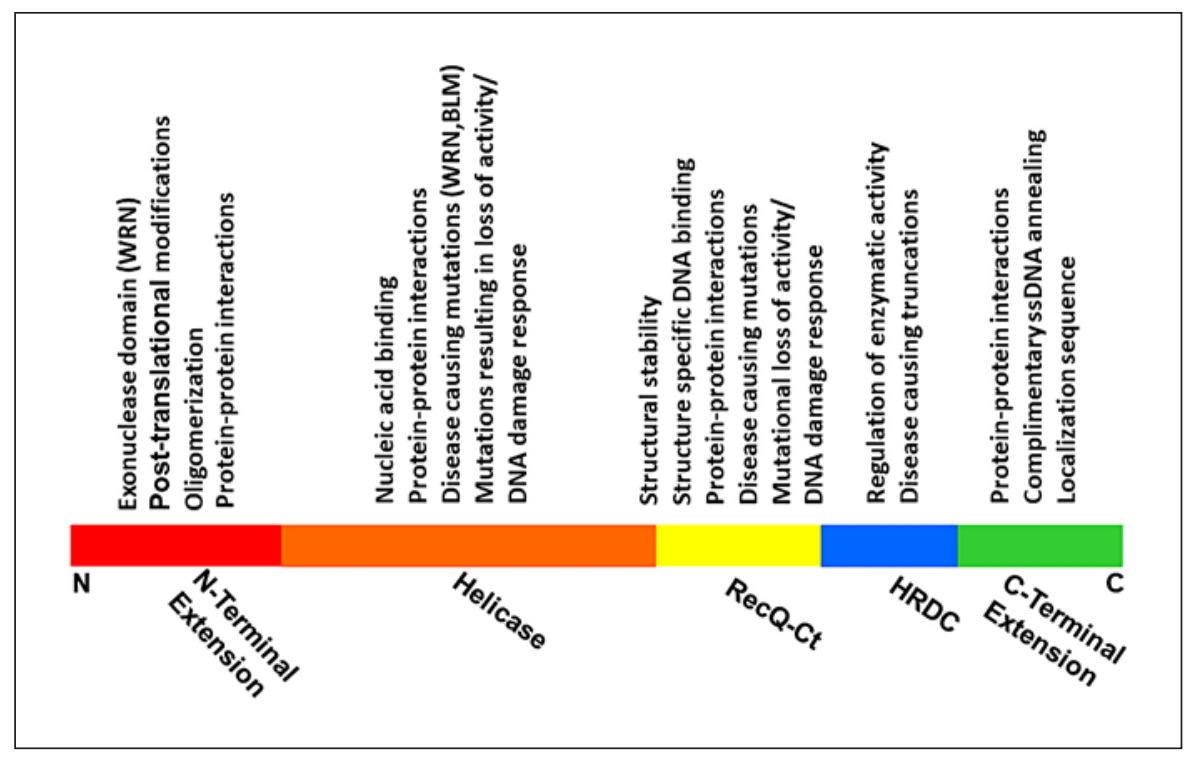

WS, BS, RTS, BGS, and RAPADILINO patients showed a reduced proliferation potential in vitro suggesting an important role for BLM, WRN, and RecQL4 proteins in the DNA replication process [Bennett and Keck, 2004]. Cells derived from WS, BS, and RTS display unique chromo- some abnormalities: variegated translocation mosaicism in WS [Salk et al., 1981], elevated sister chromatid exchanges in BS [Chaganti et al., 1974], and aneuploidy [Ying et al., 1990] in RTS. Cytogenetic studies are highly restricted in the cells of BGS patients, and premature cen- 
Table 3. DNA damage sensitivity of human RecQ helicase-deficient cells

\begin{tabular}{llll}
\hline Types of DNA damage & Werner & $\begin{array}{l}\text { Bloom } \\
\text { syndrome }\end{array}$ & $\begin{array}{l}\text { Rothmund-Thomson } \\
\text { syndrome }\end{array}$ \\
\hline Oxidative DNA damage (hydrogen peroxide) & $+++[1-4]$ & $+++[5-7]$ & $+++[8-10]$ \\
Bulky DNA adducts (UV and 4-nitroquinoline oxide) & $+++[3,11]$ & $+++[12]$ & $++[13,14]$ \\
DNA double-strand breaks (ionizing radiation, camptothecin, and doxorubicin) & $+++[15]$ & $+++[15]$ & $+++[13]$ \\
DNA replication blockage (hydroxyurea) & $+++[15]$ & $+++[15]$ & $++[14]$ \\
DNA crosslinks (cisplatin and mitomycin C) & $+++[15]$ & $+++[15]$ & $++[13]$ \\
DNA alkylating agents (methyl methanesulfonate and ethyl methanesulfonate) & $+++[16]$ & $+++[17-20]$ & NA \\
Mutation (N-ethyl-N-nitrosourea) & NA & $+++[18]$ & NA \\
\hline
\end{tabular}

Data obtained from the following references: [1] Werner et al., 2006; [2] Woo et al., 2006; [3] Schurman et al., 2009; [4] Poot et al., 2001; [5] Poot et al., 2002a; [6] Motegi et al., 2004; [7] von Kobbe et al., 2004; [8] Nicotera et al., 1989; [9] Nicotera, 1991; [10] Nicotera, 1994; [11] Poot et al., 2002b; [12] Shiraishi and Sandberg, 1979a; [13] Jin et al., 2008; [14] Fan and Luo, 2008; [15] Mao et al., 2010; [16] Imamura et al., 2002; [17] Krepinsky et al., 1979; [18] Kurihara et al., 1987;[19] Shiraishi, 1985; [20] Shiraishi and Sandberg, 1979b. ++ , Moderate sensitivity; +++, elevated sensitivity; NA, data not available.

tromere separation was reported in an earlier study [Huson et al., 1990]. Cells deficient in WRN, BLM, and $R E C Q L 4$ genes show elevated sensitivity to a wide variety of DNA damaging agents such as UV, 4-nitroquinoline-1 oxide (4NQO), DNA crosslinking agents, alkylating agents, and chemotherapeutic drugs [Krepinsky et al., 1979; Shiraishi and Sandberg, 1979a, b; Shiraishi, 1985; Kurihara et al., 1987; Nicotera et al., 1989; Nicotera, 1991, 1994; Poot et al., 2001, 2002; Von Kobbe et al., 2004; Werner et al., 2006; Woo et al., 2006; Fan and Luo, 2008; Jin et al., 2008; Schurman et al., 2009; Mao et al., 2010; Motegi et al., 2016]. Data on DNA damage sensitivity of RecQ deficient cells are summarized in Table 3.

Mutation analysis of each of the disease causing genes (WRN, BLM, and RECQL4) was carried out by researchers to determine the cause-effect relationship for the manifestation of clinical features in WS, BS, and RTS, BGS, and RAPADILINO patients. Yu et al. [1996] identified 2 splice-junction mutations and 2 nonsense mutations in the WRN gene of 4 patients with WS. Subsequent studies [Monnat et al., 1992; Oshima et al., 1996; Goto et al., 1997; Moser et al., 1999] indicated that as much as $80 \%$ of mutations detected in the WRN gene of Japanese Werner patients led to the lack of detection of mutated protein, equivalent to that of null alleles. It is logical to assume that the complete absence of WRN protein in the cells of WRN patients could favor the development of multiple neoplasms since WRN plays important roles in the maintenance of genomic instability. Lauper et al. [2013] analyzed a population of 189 WS patients with 248 neoplasms of which thyroid neoplasm, malignant melanoma, meningioma, soft tissue sarcoma, and leukemia were predominant. A recent review summarizes the spectrum of mutations found in the 5 human RecQ helicases that are associated both with disease outcome and cancer incidence [Mojumdar, 2020]. The frequency of cancer incidence is predominant in BS followed by WS and RTS patients. Most causative mutations for BS are localized at the helicase, RQC, and HRDC domains, but the mutations associated with cancer are spread through the entire length of the BLM gene. However, some of the truncation and frameshift mutations found at the $\mathrm{N}$-terminal flanking region of BLM helicase domain are found associated with both cancer incidence and BS [Mojumdar, 2020]. A molecular link between carriers of deleterious BLM mutations and colorectal cancer has been documented [de Voer et al., 2015]. An oncogenic role was recently proposed for RecQL5 in human breast cancer [Arora et al., 2016a], and a decreased RecQL5 level correlated well with the progression of osteosarcomas [Wu et al., 2015]. Missense mutations in RecQL1 have been shown to correlate with familial breast cancer [Arora et al., 2017; Debnath and Sharma, 2020].

Most mutations detected in RTS, BGS, and RAPADILINO patients were localized in the helicase domain, resulting in a truncated RecQL4 protein [Kitao et al., 1999; Siitonen et al., 2003; Van Maldergem et al., 2006]. Humans afflicted with RTS and RAPADILINO show an increased risk for developing lymphoma and osteosarcoma, thus highlighting the correlation between RecQL4 loss and cancer incidence [Lu L et al., 2014]. While WS and BS patients develop multiple neoplasms, RecQL4 deficient RTS patients predominantly develop osteosarcoma [Hanada and Hickson, 2007]. Lindor et al. [2000] reported 
compound heterozygous mutations in RECQL4 of 2 brothers afflicted with RTS, and one of the brothers died at 9 years of age due to osteosarcoma of the right calcaneus and right iliac wing. The other brother was diagnosed at 21 years of age with osteosarcoma of the distal radius. Simon et al. [2010] described 2 novel compound heterozygous RecQL4 mutations (c.1919_1924delTCACAG, p.L640_A642delinsP in exon 12 of the RECQL4 gene and mutation c.1704+1G $>\mathrm{A}$ in intron 10 of the RECQL4 gene in a RTS type II patient. The patient developed multiple malignancies: (1) large cell anaplastic T-cell lymphoma at 9 years of age, (2) diffuse large B-cell lymphoma and osteosarcoma at 14 years of age, and (3) acute lymphatic leukemia at 21 years of age. One of the compound heterozygous mutation was mapped to exon 12 of the conserved helicase domain of RecQL4. As RecQ helicases have demonstrated roles in diverse DNA metabolic activities such as replication, transcription, repair, and recombination [Bochman, 2014; Croteau et al., 2014], increased incidence of multiple neoplasms in BS, WS, and RTS is somewhat an expected outcome since mutational inactivation of RecQ genes could trigger oncogenic processes through accumulation of genomic instability.

In sharp contrast to increased incidence of multiple cancers observed in RecQ helicase-deficient human syndromes, increased expressions of human RecQ helicases have been detected in multiple human cancers. Elevated expression of RecQL4 was first reported in human sporadic osteosarcoma [Maire et al., 2009] and prostate cancer [Su et al., 2010] samples. Subsequently, observations of elevated levels of RECQL4 gene amplification (30.6\%), RECQL4 mRNA (51\%), and RecQL4 protein (23\%) in breast cancer cells were found associated with tumor aggressiveness and HER2 overexpression [Arora et al., 2016a]. Elevated RecQL4 expression was also observed in cervical [Choi et al., 2007], laryngeal [Saglam et al., 2007], gastric [Mo et al., 2016], and oral [Yong et al., 2014] cancers. Overexpression of BLM was demonstrated in colorectal cancer patients [Votino et al., 2017] and in 33\% of cisplatin-sensitive triple negative breast cancer cohorts [Birkbak et al., 2018]. Increased expression of RecQL5 was recently observed in non-small cell lung cancer cells, and the elevated RecQL5 expression correlated well with metastasis promotion and cisplatin resistance [Xia et al., 2021].

The forgoing account clearly illustrates that loss or gain of expression of RecQ helicases is linked with cancer susceptibility. Therefore, several studies have suggested the possibility of targeting RecQ helicases for cancer therapy [Sharma et al., 2005; Gupta and Brosh, 2007; Xi, 2007; Arai et al., 2011; Futami and Furuichi, 2014; Moles et al., 2016; Dhar et al., 2020]. Since RecQ helicases play important roles in DNA repair, targeting them may constitute an innovative strategy for sensitizing the cancer cells to radioand chemotherapeutic agents [Jain et al., 2020]. One of the key features that distinguishes normal cells from cancer cells is their infinite replication potential both in vivo and in vitro. In general, cancer cells have a hyperdiploid number of chromosomes ( $>46)$ relative to 46 in normal cells necessitating a robust replication machinery for cancer cells. Increased expression of RecQ helicases in a wide variety of human cancers raises a likely possibility that they can fulfill the replication demand of cancer cells. Hanahan and Weinberg [2000] identified 6 hallmark capabilities for cancer: (1) maintenance of proliferative signaling, (2) evasion of cell cycle regulation, (3) evasion of cell death, (4) activation of invasion and metastasis, (5) gain of replicative immortality, and (6) promotion of angiogenesis. This review attempts to highlight some of the above-mentioned cancer hallmark capabilities of RecQL4 and its potential significance as a novel molecular therapeutic target for RecQL4 overexpressing cancer cells. It must be emphasized that not all cancer cells show increased RecQL4 expression, and there are many routes for carcinogenesis that can occur independent of RecQL4.

\section{Sustained Proliferation Capacity in RecQL4 Overexpressing Cancer Cells}

Although 6 well-defined capabilities are crucial for cancer development processes, it is not clear whether cells on a malignant path acquire them either simultaneously or sequentially. Nevertheless, it is widely accepted that acquisition and sustenance of an infinite replicative potential are key factors for carcinogenesis. Retarded growth potential of human cells deficient in BLM, WRN, and RecQL4 gave a general indication that RecQ helicases participate in DNA replication [Bennett and Keck, 2004; Burla et al., 2018; Schmit and Bielinsky, 2021]. Since this review is focused on RecQL4, much of the discussion is confined only to RecQL4 and its associated activities in DNA replication.

Sangrithi et al. [2005] provided the first biochemical evidence for the role of RecQL4 in the DNA replication initiation process. An essential function for the Drosophila homolog of RecQL4 in DNA replication during development was demonstrated by Wu et al. [2008]. Further, retarded proliferation, chromosomal fragmentation, and developmental lethality were observed in Drosophila Rec- 


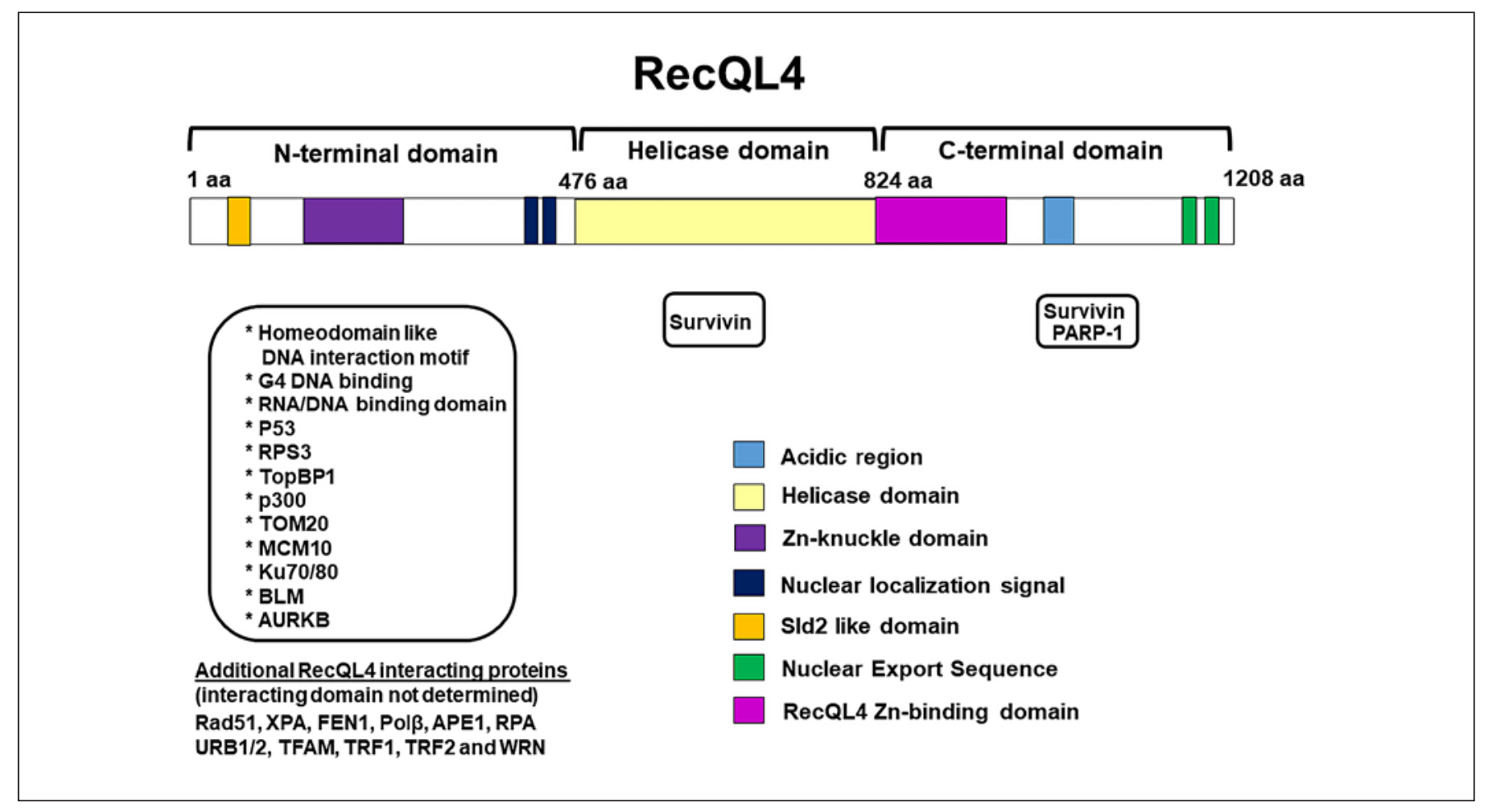

Fig. 3. Schematic representation of N-terminal, helicase, and Cterminal domains of RecQL4 and its interacting proteins. The Nterminal domain exhibits DNA binding activities and is found esssential for DNA replication initiation and cell viability in vertebrate cells. The C-terminal domain confers genome stability and survival through interaction with survivin and poly(ADP)ribose polymerase 1 . The helicase domain exhibits ATPase activity, DNA

QL4 homomorphic mutants. Subsequent studies provided further insights into the role of RecQL4 in replication origin firing, and the forced tethering of RecQL4 on prereplication complex leads to replicative stress in human cells by inducing unscheduled activation of DNA replication origin [Im et al., 2009, 2015; Kliszczak et al., 2015; Shin et al., 2019]. Capp et al. [2010] suggested that RecQL4 may serve as the second replicative helicase, and this exciting possibility remains to be investigated.

One feature that distinctly separates RecQL4 from other human RecQ helicases is the presence of an Sld2like domain at the N-terminal region of RecQL4 (Fig. 1). A schematic diagram showing the structure of human RecQL4 as well as proteins interacting with different functional domains of RecQL4 protein are shown in Figure 3. The Sld2-like domain is clearly involved in DNA replication initiation in yeast $S$. cerevisiae [Tanaka et al., 2007], Drosophila [Crevel et al., 2012], and Xenopus [Matsuno et al., 2006] model systems. It is worth noting that binding and DNA unwinding activities. Survivin interacts with both helicase and C-terminal domains. The N-terminal domain interacts with proteins involved in DNA replication, repair, telomere regulation, ribosome biogenesis, and mitochondrial replication. RecQL4 interacting domain has not been determined for 12 additional proteins but their interactions with RecQL4 have been experimentally validated. mutations have not been identified in the Sld2-like domain in any of the human RecQL4 deficient syndromes (RTS, RAPADILINO, and BGS) indicating that this region is probably protected against mutations. It is not known whether mutations in the $\mathrm{N}$-terminal, helicase, and C-terminal domains of RecQL4 affect the functionality of Sld2-like domain in DNA replication initiation. Additionally, the $\mathrm{N}$-terminal part has a cysteine-rich region and $\mathrm{Zn}$ knuckle domain that binds to a variety of nucleic acid substrates [Marino et al., 2016]. Observations of developmental lethality in RecQL4 N-terminal deletion mutants and partial complementation of DNA replication defects in RTS depleted Xenopus extract by N-terminal region of human RecQL4 suggest that the RecQL4 $\mathrm{N}$-terminal domain is crucial for both organismal viability and DNA replication initiation. However, partial DNA replication recovery ( $20 \%$ of wild type) by the $\mathrm{N}$ terminal region points out that other RecQL4 domains (helicase and C-terminal domains) are necessary for 
complete complementation. Ohlenschläger et al. [2012] identified that the first 54 amino acids at the $\mathrm{N}$-terminal of RecQL4 (RecQL4_N54) interact with topoisomerase binding protein 1 (TopBP1), and this homeodomain-like motif binds to DNA without any sequence specificity but with a high preference to single-stranded DNA and Yshaped DNA. The homeodomain-like motif is considered to be a hallmark feature of many replication initiation factors including yeast Sld2. In addition to these unique DNA-binding features at the $\mathrm{N}$-terminus, several important DNA replication and repair proteins have been found to interact with the $\mathrm{N}$-terminal domain of RecQL4 (Fig. 3). Some of these include p53, p300, ribosomal protein S3, Ku70/80, MCM10, BLM, TOM20, and aurora kinase B. Abe et al. [2011] showed that the N-terminal domain of RecQL4 is sufficient for proliferation and survival of vertebrate cells. It is interesting to note that RecQL4 proficient cells derived from WS patients also showed retarded growth potential in vitro due to a combination of proliferation failure and replicative senescence. Observations of proliferation failure in primary cells of both RTS and WS patients [Hanada and Hickson, 2007] indicate that both RecQL4 and WRN helicases play mutually exclusive roles in forming an efficient DNA replication initiation complex, and the functional loss of one helicase cannot be compensated by the other.

Amplification of RecQL4 has been reported in earlier studies [Maire et al., 2009; Su et al., 2010; Fang et al., 2013; Arora et al., 2016b; Chen et al., 2018]. Interestingly, multiple human cancer cells display gain of chromosome $8 \mathrm{q}$ (long arm) and loss of chromosome $8 p$ (short arm) that contain RECQL4 and WRN genes, respectively [Knuutila et al., 1998; Parada et al., 1998; Qian et al., 1998; Griffin et al., 2007; Salahshourifar et al., 2014; Sana and Malik, 2015; Shields et al., 2019]. Increased copies of the chromosome $8 \mathrm{q}$ distal region (8q22q24) were observed in human metastatic prostate cancer cell lines, and the highly metastatic PC3 cell line displayed as many as 6 copies of chromosome 8q distal region [Su et al., 2010]. RecQL4 mRNA expression was 65 -fold higher in metastatic breast tumor tissues than in normal tissues [Fang et al., 2013]. The 8q24 region also harbors an important oncogene, $M Y C$, that is amplified in several human cancers [Hsieh et al., 2015; Stine et al., 2015]. Consistent with an increased copy number of 8q distal region, RecQL4 expression was also elevated in all the 3 metastatic prostate cancer cell lines (DU145, LNCaP, and PC3) at mRNA and protein levels. RecQL4 suppression in prostate cancer cells reduced their proliferation potential in vitro as well as their tumorigenic potential in vivo as judged by the tu- mor volume in mouse xenografts. Similar inhibitory effects were reported in human breast cancer cells after RecQL4 suppression [Fang et al., 2013]. Additionally, RecQL4 suppressed prostate and breast cancer cells showed increased DNA damage accumulation and enhanced sensitivity to DNA damaging agents [ $\mathrm{Su}$ et al., 2010; Fang et al., 2013; Mo et al., 2016]. Zhu et al. [2018] recently examined the prognostic value of all the 5 RecQ helicases based on their mRNA expression in patients with breast cancer. While increased overall survival and cancer-free survival were found associated with elevated expression of WRN mRNA, reduced overall survival, distant metastasis-free survival, and cancer-free survival were all reduced in patients with increased RECQL4 mRNA expression. On the other hand, increased expression of BLM mRNA was found associated mainly with reduced distant metastasis-free survival in all the breast cancer patients. Interestingly, overexpression of RECQL1 mRNA improved overall survival of patients with basallike breast cancer and patients with p53 mutated breast cancer. Overexpression of RECQL5 mRNA improved the cancer-free survival of all the patients, overall survival of lymph-node negative breast cancer patients but reduced the overall survival of patients with HER-2 positive breast cancer. It is obvious from the foregoing account that overexpression of RECQL4 mRNA has far more deleterious effects on breast cancer patient survival than other RecQ helicases. Similar to breast cancer, elevated RecQL4 expression was found associated with poor prognosis in gastric cancer patients [Chen et al., 2018].

A role for RecQL4 in the formation and assembly of the DNA replication initiation complex has been demonstrated in yeast, Drosophila, Xenopus, and mammalian model systems including humans [Matsuno et al., 2006; Tanaka et al., 2007; Thangavel et al., 2010; Crevel et al., 2012]. As cancer cells often have hyperdiploid DNA content, the total amount of DNA to be replicated in cancer cells is expected to be at least 1.5-2-fold more than in normal cells, and this may require a substantial increase in the expression of proteins involved in DNA replication initiation and elongation. Increased expression of RecQL4 may fulfill the increased replication demand of cancer cells as a DNA replication initiation factor. This notion is supported by an elevated expression of RecQL4 and other RecQ helicases in virus-immortalized human cells that require sustained proliferative capacity for their survival [Kawabe et al., 2000]. Proliferation failure and apoptosis observed in both prostate and breast cancer cells [Su et al., 2010; Fang et al., 2013] by RecQL4 suppression further illustrate the importance of RecQL4 in DNA 


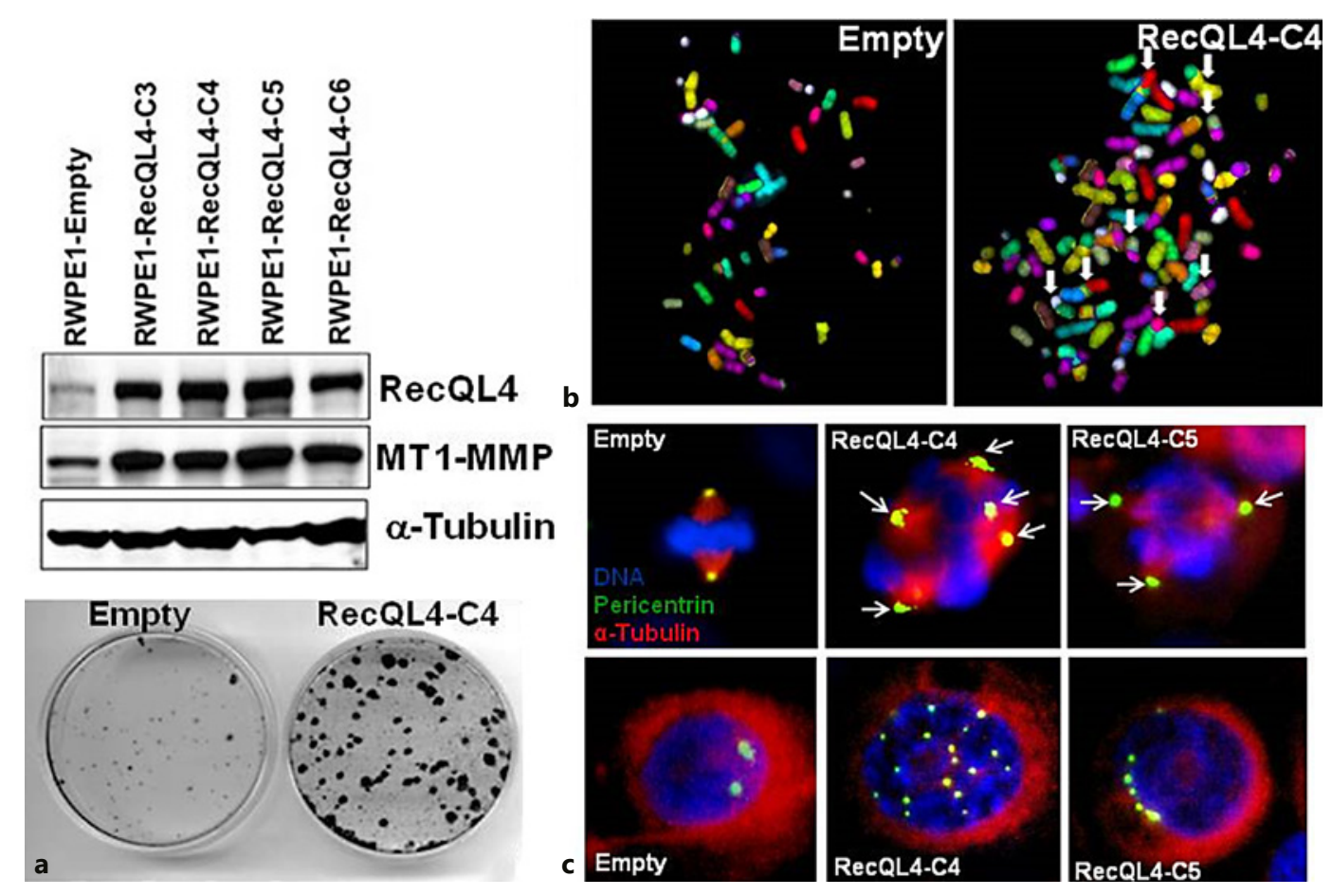

Fig. 4. a RecQL4 and matrix metalloproteinase 1 (MT-MMP1; a key player in cancer metastatic process) levels were substantially enhanced in various stable clonal cell lines $(\mathrm{C} 3, \mathrm{C} 4, \mathrm{C} 5$, and C6) of non-malignant prostate epithelial cells (RWPE1) after transfection with RecQL4 expression vector. b Both numerical and structural chromosome alterations were elevated in RecQL4 overexpressing

replication in cancer cells. Likewise, suppression of some of the DNA replication initiation proteins (Cdc6, MCM2, and Cdc45), either by antisense oligodeoxynuclotides or by siRNA, led to inhibition of DNA replication and cell growth together with apoptosis in multiple human cancer cell types independent of the functional status of p53 [Feng et al., 2003]. Occurrence of osteosarcoma in RecQL4 mutated RTS patients and increased expression of RecQL4 in osteosarcoma samples of non-RTS patients suggest that deregulated RecQL4 expression can cause tumorigenesis [Lu L et al., 2014]. Maciaszek et al. [2019] analyzed germline sequence data of 5,562 pediatric cancer patients and found that 24 of the patients had RecQL4 variants. Of interest, 9 of the 24 patients had the same variant (c.157delT; p.Cys525Alafs) in the helicase domain, indicating that the disruption of the helicase domain is crucial for oncogenic processes.

To address the question of whether elevated RecQL4 expression enhances proliferation and initiates some of cells relative to empty vector transfected cells. Chromosomes with simple and complex translocations are marked by arrows. c Forced expression of RecQL4 in normal prostate epithelial cells showed multipolar bodies and centrosome amplification similar to cancer cells. Cells were stained for pericentrin (green) and a-tubulin (red).

the cancer development processes, biological consequences of RecQL4 overexpression were investigated in non-tumorigenic prostate epithelial cells (RWPE1; manuscript in preparation). RecQL4 was stably overexpressed in RWPE1 cells using RecQL4 expression vector with a CMV promoter (pCMV6-XL5). Several clonal cell lines with stable RecQL4 overexpression were established after selection with G418 (Fig. 4), and 2 clones (clones 4 and 5) having RecQL4 expression similar to the metastatic PC3 cells were chosen for further characterization. Clonogenic survival revealed a striking increase both in the number and size of the colonies in RECQL4 expression vector transfected cell lines as compared to empty vector transfected cells (Fig. 4a). Additionally, forced RECQL4 overexpression initiated both structural and numerical chromosome alterations in RWPE1 cells (Fig. 4b). The chromosome number ranged from 45 to $51 /$ metaphase in both parental RWPE1 and empty vector transfected RWPE1 cells. In contrast, the chromosome number 
ranged from 62 to 74/metaphase in RecQL4 overexpressing cells. In addition to numerical alterations, RECQL4 overexpression also resulted in 5-8 simple and complex translocations involving multiple chromosomes $(1,4,5$, $8,14,17$, and 18; Fig. 4b, marked by arrows). These data clearly illustrate that RecQL4 overexpression triggers chromosomal instability, a key feature for initiation and progression of tumorigenic events. RecQL4 overexpression also resulted in an increased frequency of polyploidy (25-35\% of total cells) in RWPE1 cells. While the majority of cells (87\%) in empty vector transfected RWPE1 cells showed 1-2 centrosomes, more than $60 \%$ of RecQL4 overexpressing cells showed centrosomes ranging from 3 to 18 in number (Fig. 4c). Consistent with increased centrosome numbers, multipolar spindles were also observed in $44 \%$ of the mitotic cells in RECQL4 overexpressing clonal cell lines (C4 and C5) of RWPE1 (Fig. 4c). Observation of increased centrosome number and multi-polar spindles suggests that RECQL4 overexpression initiates and promotes chromosomal instability in normal cells.

\section{How Does Elevated RecQL4 Expression Confer Proliferative Advantage to Cancer Cells?}

It is known that many replication proteins are overexpressed in cancer cells including the replication accessory factor for DNA polymerase $\delta$, proliferating cell nuclear antigen (PCNA). PCNA plays critical roles in diverse cellular activities of DNA replication, repair, cell cycle progression, and chromosome and chromatin maintenance [González-Magaña and Blanco, 2020]. Different PCNA isoforms have been reported in normal and malignant cells - the former with a single and the latter with 2 isoforms [Shen et al., 2011]. These PCNA isoforms resulting from post-translational modifications have been suggested to reduce DNA replication fidelity, thereby causing the accumulation of genetic alterations needed for the growth potential of malignant cells. Thus far, PCNA isoforms characteristic of breast [Malkas et al., 2006] and prostate [Wang et al., 2011] tumors have been identified, and antibodies against these isoforms are useful for prognosis and diagnosis. In sharp contrast to RecQL4, PCNA does not have any enzymatic activity, and its contribution to DNA replication is mainly through interaction with other proteins involved in "replisome" or "synthesome." Analogous to PCNA, RecQL4 may also exist in different isoforms in malignant cells and this aspect remains to be investigated. RecQL4 suppression in non-malignant epithelial cells reduced the proliferation only by $20 \%$ relative to more than $50 \%$ in prostate cancer cells [Su et al., 2010]. This observation raises the possibility that the replication dependency on RecQL4 is perhaps more for cancer cells than for apparently normal non-malignant prostate epithelial cells. Evidence for the stimulation of RecQL4 helicase activity through phosphorylation of serine residues (89 and 251) by cyclin dependent kinases 1 and 2 (CDK1 and 2) has been obtained by Lu et al. [2016], and this finding suggests that post-translational modifications can potentially increase the activities of RecQL4. Future studies are warranted to determine whether or not post-translational modifications of RecQL4 enhance the DNA replication fidelity of cancer cells.

\section{RecQL4 Maintains Cell Cycle and Mitotic Integrity in Cancer Cells}

Kawabe et al. [2000] first demonstrated the cell cycle distribution of RecQL4 protein expression, which was abundant in S and G2/M phases in virus-transformed human B lymphocytes. Cell cycle-specific expression of RecQL4 was found analogous to BLM protein suggesting that both RecQL4 and BLM helicases may play specific roles during S and G2/M phases. Suppression of RecQL4 in prostate cancer cells resulted in the accumulation of apoptotic sub-G1 population indicating the loss of G2/M checkpoint regulation [Su et al., 2010]. In another study, RecQL4 suppression in osteosarcoma (U2OS) cells resulted in a gradual accumulation of $\mathrm{G} 2 / \mathrm{M}$ phase cells from $28.31 \%$ to $46.17 \%$ after $72 \mathrm{~h}$ of culture and then declined to $29.81 \%$ after $96 \mathrm{~h}$. The decline in G2/M phase cells at $96 \mathrm{~h}$ was accompanied by an increase in sub-G1 apoptotic cells (30.45\%) probably owing to mitotic irregularities involving mitotic spindle apparatus with malsegregation of chromosomes [Fang et al., 2018]. Mitotic integrity is crucial for survival of normal and cancer cells, and mitotic irregularities resulting from mitotic checkpoint defects often lead to cell death. Two lines of evidence indicate a pivotal role for RecQL4 in mitotic integrity: (1) RecQL4-deficient cells from RTS patients are characterized by aneuploidy [Lindor et al., 1996] and (2) RecQL4-suppressed osteosarcoma cells displayed an elevated apoptotic death owing to mitotic irregularities [Fang et al., 2018]. Trisomy 8 mosaicism was found in the cells of 2 of the 3 RTS patients examined [Lindor et al., 1996]. In general, chromosome aneuploidy is detrimental at the cellular and organismal levels as in the case of human Down syndrome patients with an extra copy of chromosome 21. Aneuploidy observed in cells of some of the 
RTS patients suggests the involvement of RecQL4 in the maintenance of mitotic integrity. In corroboration, a recent study shows that RecQL4 is a microtubule-associated protein and is critical for microtubule stability and kinetochore attachment [Yokoyama et al., 2019]. Additionally, RecQL4 downregulation in HeLa cells resulted in the misalignment of chromosomes with delayed mitosis progression [Yokoyama et al., 2019]. In the absence of RecQL4, chromosome misalignment could potentially lead to aneuploidy and mitotic catastrophe as observed in RTS cells and RecQL4-suppressed cancer cells [Fang et al., 2018]. Observations of aneuploidy and hyperdiploidy clearly suggest a compromised mitotic checkpoint machinery in cancer cells. It is not clear how hyperdiploidy (gain of several chromosomes) is tolerated in cancer cells and whether or not this tolerance stems from evasion of cell death.

Mitosis is a crucial cell cycle phase where faithful chromosome segregation occurs between 2 daughter cells. Mitosis is regulated by a number of protein kinases among which Aurora kinases (A, B, and C) have gained prominence due to their concerted roles in spindle checkpoint assembly and control. Aurora B kinase constitutes an important component in the chromosome passenger complex (CPC). The CPC is a hetero-tetrameric complex of an enzymatic (aurora B kinase, AURBK) and 3 regulatory protein components (inner centromere protein [INCENP], survivin and Borealin) and the regulatory components control the activity and localization of $\mathrm{Au}$ rora $\mathrm{B}$. The $\mathrm{CPC}$ is responsible for mediating several mitotic activities such as prevention of chromosome-microtubule attachment errors, spindle assembly checkpoint activation, and regulation of cytokinesis [Vader et al., 2008; Tseng et al., 2010; Carmena et al., 2012]. Ectopic overexpression of Aurora B causes aneuploidy in cancer cells, and forced overexpression of Aurora B in mice led to the development of aneuploidy and multiple spontaneous tumors [Gonzalez-Loyola et al., 2015]. Additionally, Aurora B overexpression also diminished the DNA repair response as well as the expression of $\mathrm{p} 21$, a critical cell cycle and DNA repair target for the major tumor suppressor gene, p53 [Gonzalez-Loyola et al., 2015]. It was demonstrated for the first time [Fang et al., 2018] that the Nterminal region of RecQL4 interacts with the catalytic domain of Aurora B in 293T cells and stabilizes its expression by inhibiting Aurora B ubiquitination. As expected, RecQL4 suppression in U2OS cells resulted in the reduced expression of Aurora $B$ due to ubiquitin-mediated degradation suggestive of RecQL4 being an upstream target for Aurora B. It remains to be investigated whether or not Aurora B-RecQL4 axis is crucial for the maintenance of hyperploidy and tumorigenicity. Analogous to RecQL4, increased Aurora B expression has been observed in non-small cell lung cancer, oral squamous cell carcinoma, gastric cancer, and breast cancer [Pannone et al., 2011; Al-Khafaji et al., 2017; Chen et al., 2018; Huang et al., 2019]. Aurora B overexpression correlates with poor prognosis and contributes to increased drug resistance in breast cancer [Zhang et al., 2015]. Since RecQL4 expression was not analyzed in the above-mentioned studies, it is difficult to determine the importance of RecQL4-Aurora B axis in cancer prognosis and drug resistance. Increased incidence of osteosarcoma in RTS patients with inactivating mutations in RecQL4 certainly point out that cancer development processes can occur by multiple routes without involving RecQL4. Nevertheless, mitotic irregularities imposed by the suppression of either RecQL4 or Aurora B suggest that RecQL4-Aurora B axis is important for cell cycle regulation and maintenance of mitotic integrity in cancer cells. Recently, mutations in anaphase promoting complex 1 gene (ANAPC1) have been found to be the genetic cause of RTS type 1 patients who have increased susceptibility for juvenile cataracts [Ajeawung et al., 2019]. Although the genetic cause is different for RTS type 1 and type 2 patients, their overall phenotypic similarities suggest the possibility that both ANAPC1 and RECQL4 genes have overlapping functions since deficiencies either in APC or RecQL4 result in the dysregulation of pathways governing chromosomal stability and cell cycle regulation. Anaphase promoting complex (APC) is a multi-unit ubiquitin ligase that has at least 69 protein substrates, and many substrates such as CDC 20, Aurora A, Aurora B, and forehead box M1 (FOXM1) are expressed at high levels in multiple cancers [VanGenderen et al., 2020]. Out of the 69 protein substrates of APC, 60 have been implicated in tumor promotion and the rest in tumor suppression. It is worth investigating whether or not RecQL4 stabilizes the expression of some of the APC substrates by preventing their ubiquitin-mediated degradation similar to that observed for Aurora B kinase [Fang et al., 2018]. These interesting possibilities await future investigations.

\section{RecQL4 Protects Cancer Cells from Endogenous and Exogenous DNA Damage}

It is well established that RecQ helicases play crucial roles in the maintenance of genomic stability through their participation in diverse DNA metabolic pathways 
including DNA repair [Sharma et al., 2006; Brosh and Bohr, 2007; Bohr, 2008; Croteau et al., 2014; Mo et al., 2018], and cells of WS, BS, and RTS patients show enhanced sensitivity to a wide variety of DNA damaging agents (Table 3). Sensitivity of WS cells to hydroxyurea, camptothecin, and 4NQO has been previously reported [Gebhart et al., 1988; Ogburn et al., 1997; Poot et al., 1999]. Among them, hydroxyurea and camptothecin cause DNA replication blockage, while 4 NQO induces bulky DNA lesions that are substrates for the nucleotide excision repair pathway. Similar to WS cells, cells of BS are also sensitive to $4 \mathrm{NQO}$ implicating the involvement of $W R N$ and $B L M$ genes in the nucleotide excision repair pathway. Besides $4 \mathrm{NQO}$, BS cells were also shown to be sensitive for N-ethyl-N-nitrosourea, ethyl methanesulfonate, methyl methanesulfonate, and UV radiation [Krepinsky et al., 1979; Shiraishi and Sandberg, 1979a; Shiraishi, 1985; Kurihara et al., 1987]. Imamura et al. [2002] demonstrated that chicken DT40 cells deficient in both WRN and BLM exhibited several folds more sensitivity to a wide variety of genotoxic agents such as methyl methanesulfonate, 4NQO, etoposide, UV, and camptothecin than cells of single mutants either for WRN or BLM. Observation of synergistic increase in the cellular sensitivity of WRN and BLM double mutants suggests that WRN and BLM proteins participate in DNA repair pathways in a complementary manner. Human primary fibroblast cells deficient in RecQL4 showed hypersensitivity to hydroxyurea, camptothecin, and doxorubicin and moderate sensitivity to UV, ionizing radiation, and cisplatin [Jin et al., 2008]. This finding suggests that replication blocking agents potentiate the sensitivity of RecQL4-deficient cells consistent with the established roles of RecQL4 in DNA replication initiation [Im et al., 2009, 2015; Kliszczak et al., 2015] and in the re-initiation of stalled replication forks after exogenous DNA damage [Masai, 2011].

Earlier studies showed the interaction of RecQL1 with DNA double-strand break (DSB) repair, mismatch repair, and base excision repair proteins [Doherty et al., 2005; Sharma and Brosh 2007; Sharma et al., 2012; Parvathaneni et al., 2013; Sami et al., 2015]. Using the mouse model system, Sharma et al. [2007] provided an indirect evidence for the DNA repair role for RecQL1 in the suppression of chromosome instability. Human cervical cancer cells deficient either in WRN or in RecQL1 were shown to behypersensitive to hydroquinone and benzo(a) pyrene exposure indicating the participation of both WRN and RecQL1 proteins in the DSB repair pathway [Garige and Sharma, 2014]. Similar to RecQL1, RecQL5 also participates in DNA DSB repair [Schwendener et al.,
2010; Maruyama et al., 2012; Paliwal et al., 2014], and the recruitment of RecQL5 to the sites of DNA DSBs depends on its interaction with a primary DSB sensor complex of 3 proteins: MRE11, RAD50, and NBS1 [Zheng et al., 2009]. It is interesting to note that RecQL4, like the rest of the RecQ helicases (RecQL1, WRN, BLM, and RecQL5) is also involved in the repair of DNA DSBs [Singh et al., 2010; Shamanna et al., 2014]. Prior to these studies, Kumata et al. [2007] showed for the first time a direct involvement of RecQL4 in DNA DSB repair in Xenopus egg extracts. In addition to DNA DSB repair, involvement of RecQL4 in base excision and nucleotide excision repair pathways has also been documented in the literature [Fan and Luo, 2008; Schurman et al., 2009].

Given the demonstrated roles of RecQL4 in diverse DNA repair pathways, it is intriguing as to whether or not elevated expression of RecQL4 will protect the cancer cells from endogenous DNA damage and increase their resistance to exogenous damage induced by radio- and chemotherapeutic agents. In human prostate cancer cells, RecQL4 suppression led to an elevated level of spontaneous DNA DSBs detected by well-known surrogate markers [Su et al., 2010]. Further, increased poly(ADP-ribose) polymerase I (PARP-1) mediated apoptotic death was observed in RECQL4-silenced human prostate cancer cells indicating a role for RecQL4 in protecting the cancer cell's genome. Evidence for a role of RecQL4 in cisplatin resistance was provided by Mo et al. [2016] by reversing the cisplatin resistance in RecQL4 overexpressing human gastric cancer cells through RecQL4 suppression. The reversion of cisplatin resistance was achieved by the loss of RecQL4 leading to transcriptional dysregulation of multi drug resistance gene 1 (MDR1) through reduced AKT phosphorylation of a major transcription factor YB1. The authors proposed that RecQL4 mediated axis of AKTYB1-MDR-1 is crucial for cisplatin resistance in RecQL4 overexpressing gastric cancer cells. Conversely, cisplatinsensitive gastric cancer cells showed resistance to cisplatin upon ectopic overexpression of RecQL4, illustrating a regulatory role for RecQL4 in the response of cancer cells to cisplatin.

Yet another evidence came from the study of Król et al. [2020] where RecQL4 suppression either by siRNA or CRISPR/Cas9 correlated well with increased temozolomide sensitivity of p53 mutant LN18 glioblastoma cells. Additionally, RecQL4 silencing in LN18 glioblastoma cells affected their mitochondrial network as well as the mitochondrial polarization. However, temozolomide sensitization was not observed after RecQL4 suppression in LN229 glioblastoma cells that have methylated 
0-6-methylguanine DNA methyltransferase (MGMT) and functional p53 genes. Further studies are required to verify the contribution of p53 in RecQL4-mediated drug resistance. Our earlier study suggested the possibility that RecQL4 can potentially regulate the expression of genes such as MDR1 and YB1 in gastric cancer cells. In support, Król et al. [2020] demonstrated that RecQL4 silencing in LN18 cells caused transcriptomic changes with 3,056 downregulated genes and 1,699 upregulated genes. Some of the downregulated genes belong to the pathways of ribosome biogenesis, RNA transport, RNA degradation, and protein synthesis in endoplasmic reticulum. Ribosome biogenesis is hyperactivated in cancer cells to fulfill the increased demand of protein synthesis for sustaining an infinite growth potential [Slimane et al., 2020]. Downregulation of ribosome biogenesis in RecQL4-suppressed glioblastoma cells suggests that RecQL4 contributes to enhanced ribosome biogenesis. Ribosome protein S3 (RPS3) physically interacts with the N-terminal domain of RecQL4 and negatively regulates its helicase activity [Patil and Hsieh, 2017]. The physical and functional interactions of RPS3 with RecQL4 were enhanced in osteosarcoma cells after oxidative stress and UV exposure suggestive of a role for RPS3 in regulating the repair activities of RecQL4.

Guo et al. [2020] demonstrated the resistance of RecQL4 overexpressing ovarian cancer cells to cisplatin, and RecQL4 suppression increased their sensitivity to both cisplatin and a PARP-1 inhibitor, olaparib. Although drug resistance has been demonstrated for RecQL4 overexpressing gastric [Mo et al., 2016], glioblastoma [Król et al., 2020], and ovarian cancer cells [Guo et al., 2020], the molecular basis for cellular resistance has not been elucidated. The cellular resistance can arise either by efficient DNA repair or by increased resistance to cell death mechanisms. The importance of the C-terminal domain of RecQL4 in RAD52-mediated single-strand annealing pathway was recently demonstrated by Kohzaki et al. [2020]. Strikingly, deletion of the RecQL4 C-terminal domain in cancer cells, but not in non-tumorigenic cells, exhibited the impairment of single-strand annealing and nonhomologous end joining activities after treatment with cisplatin and ionizing radiation. Guo et al. [2020] identified a transcription factor MAFB (V-maf musculoaponeurotic fibrosarcoma oncogene homolog B) as a downstream target of RecQL4 in ovarian cancer cells, and MAFB expression is tightly controlled by RecQL4. Inhibition of MAFB expression in ovarian cancer cells inhibited their proliferation and invasion capacities, similar to that observed after RecQL4 suppression. Recent evidence points out a role of MAFB in osteosarcoma by promoting cancer stemness and tumor aggressiveness [Chen et al., 2020]. It is likely that RecQL4 exerts its effect on cancer stemness through a positive regulation of MAFB. Data from Tumor Cell Genome Atlas (TCGA) show an association between RecQL4 expression and some of the stem cell markers such as Nestin, Musashi-1, Myc, and CD133. Further, RecQL4 expression was found to be higher in LN18 cells grown as spheres than adherent cell monolayers [Król et al., 2020]. This observation is particularly relevant because glioblastoma cells are usually rich in cancer stem cells that can cause tumor recurrence.

The aforementioned studies [Su et al., 2010; Mo et al., 2016, 2018; Guo et al., 2020; Kohzaki et al., 2020; Król et al., 2020] indicate that RecQL4 can protect cancer cells through a multitude of mechanisms: (1) upregulation of pro-survival pathway through activation of Akt and survivin, (2) increased cellular resistance through MD1-YB1 associated pathway, and (3) enhanced efficiency of DNA repair activities. Association of RecQL4 with increased cancer stemness makes RecQL4 an effective molecular target for abolishing cancer cell recurrence. It is likely that RecQL4 is essential for stem cell homeostasis in both normal and cancer cells. Evidence for a role of RecQL4 in hematopoiesis was provided by Smeets et al. [2014]. Deletion of RecQL4 in mice resulted in bone marrow failure involving cells of myeloid and lymphoid lineages with the erythroid lineage most severely impacted. RecQL4 deletion increased the apoptotic death of multipotent progenitor cells and the bone marrow failure observed in RecQL4-depleted mice was not rescued by p53, unlike in BLM-deleted mice, indicating the indispensable function of RecQL4 in bone marrow hematopoiesis. Further, the intrinsic helicase activity was found dispensable for the role of RecQL4 in hematopoiesis. Although RecQL4 deficiency did not affect the hematopoietic stem cell compartment, stem cells of RecQL4-deleted mice were not transplantable. Further studies are required to understand the role(s) of RecQL4 in normal and cancer stem cells and the potential significance of RecQL4 targeting for cancer stem cell-mediated drug resistance and recurrence.

\section{RecQL4 Contributes to Cancer Cell Survival, Invasion, and Metastasis}

Specific amplification of the RECQL4-harboring locus of chromosome 8 (8q24.3) observed in many human cancer cell types gave the first indication that elevated Rec- 
QL4 expression may be associated with cancer susceptibility/development. Ionizing radiation and chemicals are the two important treatment modalities for cancer, but the acquired resistance of certain cancer cells to both of these agents poses serious challenges to find an effective treatment option. In most cases, if not all, acquired resistance to radiation or chemotherapeutic drugs is through resistance to cellular death mechanisms. Therefore, targeting the factors that confer resistance will prove to be a better strategy for sensitizing the cancer cells. As mentioned earlier, elevated apoptosis observed in prostate and breast cancer cells after RecQL4 suppression clearly suggests that RecQL4 may confer survival advantage to cancer cells.

Survivin is a pro-survival factor, and Fang et al. [2013] demonstrated that basal and DNA damage-induced expression of survivin depends on RecQL4. RecQL4 suppression substantially reduced the expression of survivin in breast cancer cells, and the immunoprecipitation analysis revealed the interaction of helicase and C-terminal domains of RecQL4 with survivin. Further, survivin expression after oxidative DNA damage was significantly inhibited in RecQL4-suppressed breast cancer cells relative to RecQL4 overexpressing parental cells. These observations point out that RecQL4 through modulation of survivin confers survival advantage to cancer cells when challenged with endogenous and exogenous DNA damage. Besides survivin, RecQL4 silencing also reduced the expression of one of the survivin-interacting proteins, phospho-histone $\mathrm{H} 3$ in human breast cancer cells. Thus, targeting the RecQL4-survivin pathway may prove to be an effective therapeutic strategy for breast cancer. Another line of evidence coming from the study of Mo et al. [2016] on cisplatin-resistant gastric cancer cells reinforces the role of RecQL4 in enhancing cancer cell survival. This study has identified yet another pro-survival factor, Akt1, that works under the regulatory network of RecQL4. The authors proposed that the resistance of gastric cancer cells to cisplatin was achieved by RecQL4-mediated activation of the AKT-YB1-MDR1 signaling pathway. A direct interaction of RecQL4 with an oncogenic transcription/translation factor YB1 attests the role of RecQL4 in oncogenesis. Duan and Fang [2016] established a regulatory role for RecQL4 in autophagy and apoptosis in human osteosarcoma cells. Using CRISPR/Cas and RNAi technologies, an elevated level of autophagy was observed in RecQL4 knockdown and knockout U2OS cells with an increased mitochondrial content and loss of LC3 colocalization with mitochondria. Additionally, loss of RecQL4 also destabilized the tumor suppressor PTEN induced ki- nase 1 (PINK1). PINK1 plays a crucial role in maintaining mitochondria quality control by selectively targeting the damaged mitochondria for degradation.

Previous studies provided experimental evidence for the indirect roles of RecQL4 in cancer cell invasion and metastasis [Chen et al., 2020; Guo et al., 2020; Lu et al., 2020; Machlowska et al., 2020]. Su et al. [2010] provided the first evidence that RecQL4 suppression reduced the human prostate cancer cell invasion in vitro and tumor growth of mouse xenografts in vivo. These inhibitory effects were subsequently shown for RecQL4-silenced human breast cancer cells [Fang et al., 2013]. Recently, Guo et al. [2020] showed that the oncogenic migration and invasion were abolished in RecQL4 overexpressing ovarian cancer cells by silencing MAFB, a transcriptional regulator that functions as a downstream target of RecQL4. Several proteins ( $\mathrm{N}$-cadherin, $\beta$-catenin, vimentin, Slug, Snail, and MMP-7) involved in epithelial to mesenchymal transition were downregulated in RecQL4-suppressed ovarian cancer cell lines and upregulated in RecQL4 overexpressing cells [Guo et al., 2020]. Besides identifying a downstream target of RecQL4, this study [Guo et al., 2020] also identified miR-10a-5p as an upstream regulator of RecQL4, and miR-10a-5p was downregulated in ovarian cancer tissues relative to normal tissues. Ectopic expression of miR-10a-5p in RecQL4 overexpressing ovarian cancer cells reduced their migration and invasion through RecQL4 suppression implicating a crucial role for RecQL4 in mediating the oncogenic activities.

\section{RecQL4 Contributes to Replicative Immortality through p53 and Telomere/Telomerase-Associated Pathways}

Infinite replication potential is a hallmark of cancer cells, and pathways that lead to replicative senescence are often deregulated in cancer cells. Increased expression of RecQ helicases including RecQL4 was frequently found in immortalized human cells indicative of their association with replicative immortality. In corroboration, replicative senescence mediated by RecQL4 knockdown in mice led to several features that are reminiscent of RTS patients [Lu H et al., 2014]. This study further demonstrated that the replicative senescence by RecQL4 dysfunction in mice was driven by telomere length and p53 since the replicative senescence was overcome by either ectopic expression of telomerase or silencing of p53. Using mouse RecQL4 conditional knockout of the skeletal system, Lu et al. [2015] showed limb deformities and cra- 
niosynostosis with increased p53 activation in the affected tissues. Therefore, functional RecQL4 is crucial for preventing the culmination of biological effects triggered by $\mathrm{p} 53$ hyperactivation. Increased activation of $\mathrm{p} 53$ is detrimental to tissue homeostasis as it can lead to either replicative senescence or apoptotic death. It was earlier reported that p53 inhibits the expression of RecQL4 in human cells after DNA damage by suppressing its promoter activity [Sengupta et al., 2005]. Further, RecQL4 regulates the mitochondrial retention of p53 in human cells in the absence of DNA damage through direct physical interaction [De et al., 2012]. The tumor suppressor protein p53 is frequently mutated in many cancer cells, and so p53deficient cancer cells can easily achieve evasion of replicative senescence and apoptosis.

In the absence of DNA damage, the RecQL4-p53 complex resides in mitochondria of normal human cells during all the cell cycle phases with the exception of S-phase where RecQL4 relocates to the nucleus for initiating the DNA replication process. Factors for uncoupling the RecQL4 and p53 complex during S-phase remain to be identified. In human primary and metastatic cancer tissues, RecQL4 was found both in the cytoplasm and nucleus, and increased RecQL4 expression in both cytoplasmic and nuclear compartments was found associated with a reduced disease-specific survival in gastric cancer patients [Mo et al., 2016]. Burks et al. [2007] showed the requirement of a conserved block of 22 amino acid residues (365-386; exons 5-6) for nuclear retention of RecQL4. Deletion of amino acid residues 363-392 in GFPRecQL4 as well as the deletion of amino acid residues 420-463 (exon 7) that was found in all the reported RAPADILINO syndrome patients, resulted in the cytoplasmic localization of RecQL4. We earlier reported both nuclear and cytoplasmic localization of RecQL4 in gastric cancer cells, and the increased cytoplasmic expression correlated well with poor prognosis [Mo et al., 2016]. Nucleotide sequencing of RecQL4 in some of the gastric cancer cell lines did not reveal any DNA sequence alterations. It is not clear how cancer cells retain both cytoplasmic and nuclear distribution of RecQL4.

Mitochondria are the powerhouse of the cells, and mitochondrial functionality in the production of ATP is crucial for different DNA metabolic activities including DNA replication. Potentiation of mitochondrial DNA polymerase $\gamma$ activity by RecQL4 and p53 was recently demonstrated by Gupta et al. [2014]. Both RecQL4 and p53 are required for mediating the binding of polymerase $\gamma$ to the D-loop region of mitochondrial DNA. Specifically, RecQL4 mediates the polymerase $\gamma$ binding to mi- tochondrial DNA thereby increasing its exonuclease and polymerase activities. The authors found numerous somatic mutations and polymorphisms in the mitochondrial DNA of cells derived from RecQL4-deficient RTS and p53-deficient Li Fraumeni syndrome patients [Gupta et al., 2014]. The authors speculated that some of the phenotypic and cancer susceptibility features associated with RTS and LFS are likely due to mitochondrial DNA mutations driven by the loss of RecQL4 and p53.

Telomeres, comprised of TTAGGG repeats, protect the ends of the chromosomes from exonuclease degradation and prevent illegitimate chromosome end joining. In actively proliferating cells, the size of the telomere repeats tends to get reduced during each round of replication due to the inability of the replication machinery to faithfully replicate the ends of chromosomal DNA. It is estimated that approximately each chromosome end loses up to 50 bp of telomeric DNA after each round of DNA replication. Once the telomere size reaches a critical stage, cells acquire replicative senescence by activating a cascade of signaling pathways [Turner et al., 2019]. Further, the unusual secondary DNA structures such as G-quadruplex and D-loops that are formed due to G-rich nature of telomere repeats can cause obstacles for telomeric DNA replication. Ghosh et al. [2012] demonstrated a role for RecQL4 in the resolution of D-loop structures through coordination with some of the "shelterin" proteins, TRF1, TRF2, and POT1. Similarly, TRF2 stimulates the helicase activities of WRN and BLM in resolving the telomeric Dloops [Opresko et al., 2002]. Evidence for the resolution of G-quadruplex in vitro by BLM has been provided by Sfeir et al. [2009], and TRF1 plays a crucial role in this process by recruiting BLM to the telomeric sites. Importance of RecQL4 in telomere maintenance was illustrated by the elevated levels of fragile sites, sister chromatid exchanges, and DNA DSBs in cells of RTS patients as well as in RecQL4-depleted human cells [Ghosh et al., 2012]. Collectively, all the 3 helicases, RecQL4, WRN, and BLM, were shown to be involved in telomere maintenance.

It is unequivocally established that telomere shortening is a key factor for triggering replicative senescence in actively dividing non-malignant cells [Victorelli and Passos, 2017]. Cancer cells overcome replicative senescence by triggering the activation of telomerase, a reverse transcriptase enzyme that adds back the TTAGGG repeats that are lost during each round of DNA replication, and telomerase activity has been demonstrated in cancer cells. Therefore, cancer cells can overcome replicative senescence and gain replicative immortality through telomerase activation [Blasco, 2005]. In view of the demonstrated 
roles of RecQL4 in telomere maintenance, RecQL4 may contribute to replicative immortality in cancer cells. In yeast, S. cerevisiae, 2 helicases, Pif1 and human homolog of RecQL4, Hrq1, have been demonstrated to participate in telomere length homeostasis [Nickens et al., 2018]. Increased concentration of Hrq1 stimulated the telomerase activity in vitro while increased concentration of Pif1 inhibited the telomerase activity, and these helicases, when combined in in vitro reactions, either inhibited or stimulated the telomerase activity depending on the catalytic activity of the respective helicases. It is yet to be determined whether human RecQL4 helicase, similar to yeast Hrq1, also stimulates the telomerase activity of cancer cells.

In an earlier study [Fang et al., 2018], we evaluated the requirement of RecQL4 for the telomerase-mediated immortalization process using fibroblasts derived from a mother with heterozygous RECQL4 status (AG18459) and her RECQL4 homozygous son (AG18375). The son was a compound heterozygote with $\mathrm{G}$ to A substitution in exon 8 of one allele (g.2626G $>$ A) and a disrupted splicing mutation (same mutation as his mother) and 1-bp deletion at g.2286 (g.2286delT) in exon 9 resulting in a truncated RecQL4 protein. Both these mutations in exon 8 and exon 9 map to the helicase domain of RecQL4. Both AG18459 and AG18375 fibroblasts transfected with control vector showed a limited life span in vitro (4-6 population doublings). Strikingly, ectopic expression of hTERT (human telomerase reverse transcriptase) significantly extended the life span (beyond 110 population doublings) only in the fibroblasts derived from the mother (RecQL4 heterozygous carrier) but not from the son ( 30 population doublings) with compound heterozygous mutations in RecQL4. However, concurrent expression of both RecQL4 and hTERT in AG18375 fibroblasts considerably increased their life span similar to that of AG18459 fibroblasts. These observations illustrate the importance of RecQL4 in potentiating hTERT-mediated immortalization processes in human cells. Yet another interesting observation that came out of this study [Fang et al., 2018] was the elevated expression of both RECQL4 and AURKB in AG18459 cells after ectopic expression of hTERT indicating the possibility that hTERT acts upstream of RECQL4 and $A U R K B$. AURKB has been shown to stabilize telomere integrity through TRF1 regulation [Ohishi et al., 2014]. It is tempting to speculate that hTERT activation leads to RecQL4 upregulation which in turn can ensure telomere stability in cancer cells by its unwinding and DNA repair activities and through its regulation of $A U R K B$. Future studies should focus on unraveling the functional interaction between RecQL4 and hTERT and how their coordinated activities contribute to replicative immortality for cancer cells. RecQL4 is predominantly nuclear in primary cells but cytoplasmic in immortalized cells [Yin et al., 2004], and it is not known whether the cytoplasmic location of RecQL4 is driven by specific posttranslational modifications of RecQL4 during the immortalization process. As noted before, elevated expression of RecQL4 in the cytoplasm of gastric cancer patients correlated well with reduced disease-specific survival [Mo et al., 2016] indicating that cytoplasmic RecQL4 expression correlates with tumor aggressiveness. We [Chi et al., 2012] and others [Croteau et al., 2012; De et al., 2012; Gupta et al., 2014] have demonstrated that cytoplasmic RecQL4 plays crucial roles in the maintenance of mitochondrial stability, but how cytoplasmic RecQL4 contributes to tumor aggressiveness remains to be determined. There are a number of ways RecQL4 can potentially contribute to replicative immortality of cancer cells: (1) suppression of replicative senescence through regulation of p53 and its associated pathways in cells with functional p53, (2) resolution of secondary DNA structures at the telomeric regions thereby promoting telomere homeostasis, (3) regulation of telomere integrity through AURKB and shelterin proteins, and (4) potentiation of hTERT-mediated immortalization through regulation of pro-survival factors (survivin and AKT). RecQL4 can participate in all of the above mentioned processes through interaction with replication and repair proteins (Fig. 3). Therefore, targeting RecQL4 and its regulated signaling pathways in cancer cells may be an effective therapeutic strategy.

\section{RecQL4 Is a Molecular Target for Cancer Therapy}

A schematic diagram showing the potential involvement of RecQL4 in various hallmark activities of cancer is shown in Figure 5. These include (1) proliferation potential, (2) regulation of telomere homeostasis and potentiation of hTERT mediated immortalization, (3) evasion of cell cycle regulation and apoptosis, (4) promotion of pro-survival pathways, (5) regulation of cell invasion and metastatic potential, (6) cellular protection against endogenous and exogenous DNA damage, (7) maintenance of chromosome stability, and (8) regulation of mitochondrial stability. RecQL4 can mediate/modulate most of these oncogenic activities through interaction with a network of proteins. An earlier review [Croteau et al., 2014] listed a total of 15 proteins that showed interaction with RecQL4 (RPA, TOM20, TFAM, TRF1, TRF2, FEN1, 


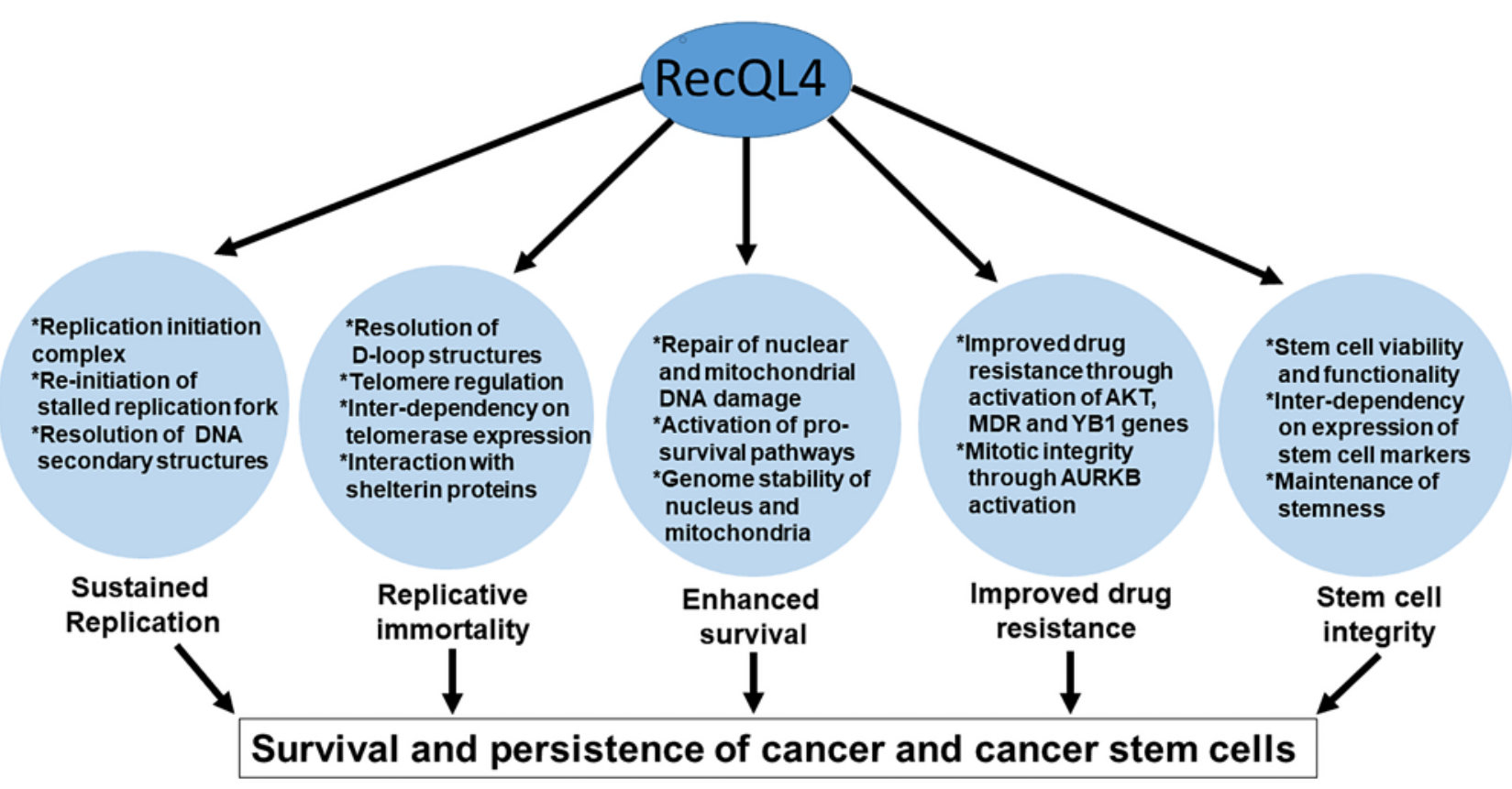

Fig. 5. Potential involvement of RecQL4 in cancer hallmark activities. (1) Sustained proliferation capacity by participating in DNA replication initiation, re-initiation of stalled replication forks after damage, and resolution of replication/transcription blocking DNA seconadry structures. (2) Replicative immortality through interaction with telomere regulatory proteins and telomere regulation by resolution of telomeric D-loop structures. (3) Enhance-

APE1, Pol $\beta$, Pol $\gamma$, PARP-1, Rad51, MCM10, p53, BLM and WRN). A search for RecQL4-interacting proteins using STRING, a biochemical data base and web source, predicted 26 additional RecQL4-interacting proteins with high scores of which experimental validation has been done only for a couple of proteins, MRE11 [Lu et al., 2016] and AURKB [Fang et al., 2018]. The rest of the proteins (ACD, ARHGAP25, BRIP1/FANCJ, FANCM, Timeless interacting protein, p300, UBR1, UBR2, MAD2L1, Mus81, TERT, Rad54B, Rad54L, Rad52, ATR, Exo1, MDC1, FBXO18, PAX1P1, MEIOB, Top3A, Top3B, XRCC3, and XRCC5) were predicted by data based on co-expression, experiments involving co-purifications/genetic interactions and textmining (searching for proteins that are frequently mentioned together in the literature). Given the demonstrated roles of RecQL4 in DNA replication and repair, it is logical to assume that RecQL4 targeting may be an effective strategy for cancer therapy. However, targeting RecQL4 or any other molecules requires a number of considerations. ment of cancer cell survival through a combination of DNA repair/ cell cycle checkpoint regulation and pro-survival pathways. (4) Cellular protection against radio- and chemotherapeutic drugs by transcriptional regulation of target genes. (V) Protection of cancer stemness and cancer stem cell viability through DNA replication and repair activities.

RecQL4 plays dual roles in both DNA replication and repair processes of normal and cancer cells. However, cancer cells have an increased demand for proliferation and survival relative to normal cells. It is known that most differentiated human cells with the exception of stem/ progenitor cells are largely non-proliferative and, therefore, targeting the replication machinery through RecQL4 may be a promising strategy. One of the major hurdles encountered with the commonly used cancer treatment modalities (ionizing radiation and chemotherapy) is the cancer recurrence most likely due to cancer stem cell populations. Cancer stem cells are shown to be highly refractory to cell death due to constitutive activation of genome surveillance and DNA repair pathways [MaugeriSaccà et al., 2013; Skvortsova et al., 2015; Abad et al., 2020]. Therefore, any effective cancer treatment strategy must include the eradication of DNA damage-resistant cancer stem cells. In this context, RecQL4 deserves a special attention here. Data from the TCGA show a positive correlation between RecQL4 expression and some of the 
stem cell markers (Nestin, Musashi-1, Myc, and CD133), indicating that RecQL4 may be critical for stemness. Król et al. [2020] showed that RecQL4 expression is higher in glioblastoma stem cells, but the size and formation of spheres rich in stem cells were greatly reduced upon RecQL4 suppression. Guo et al. [2020] showed that the transcription factor MAFB is a direct downstream target of RecQL4, and MAFB expression is tightly coupled to RecQL4 expression. Strikingly, suppression of MAFB abolishes the proliferation and invasion capacities of ovarian cancer cells, and MAFB is demonstrated to potentiate stemness in osteosarcoma [Chen et al., 2020]. RecQL4 was shown to be essential for hematopoietic stem cells in mice, and RecQL4-deficient stems cells were not transplantable [Smeets et al., 2014]. Additionally, apoptotic death was greatly elevated in multipotent progenitor cells lacking RecQL4 relative to wild-type mice. These observations point out that RecQL4 is intrinsic to stem cells, and its targeting may constitute an effective strategy for preventing the cancer recurrence through depletion of cancer stem cells. In the in vitro cell model system, RecQL4 is usually targeted by a variety of ways such as recombination-mediated deletion, point mutation, siRNA, and shRNA using mammalian expression vectors. The situation is somewhat complicated when dealing with cancer patients as the delivery of siRNA or shRNA needs to be efficient and specific to cancer cells/tissues. Knowledge of cancer cell type-specific receptors will be useful for coupling the RecQL4 siRNA for the safe delivery to cancer cells. Alternately, siRNA-coated gold nanoparticles can also be effectively used for the delivery of siRNA molecules. However, these studies have to be well-characterized for efficacy and specificity of transfer in animal model systems before proceeding to human clinical trials.

One of the ways cancer cells can acquire replicative immortality is to trigger the activation of telomerase reverse transcriptase, and available data indicate that hTERT and RecQL4 work in a concerted manner to maintain telomere integrity and stability. RecQL4 also regulates telomere homeostasis by resolving secondary DNA structures such as telomeric D-loops through its interaction with TRF1 and TRF2 [Ghosh et al., 2012] which otherwise can impede telomeric DNA replication. Given the concerted roles of RecQL4 and hTERT in telomere maintenance, RecQL4 suppression is likely to be effective for killing cancer cells and cancer stem cells by inhibiting the fidelities of DNA replication and telomere regulatory pathways. Small molecule inhibitors were used in the previous studies to block the activities of WRN [Aggarwal et al., 2011] and BLM [Nguyen et al., 2013] helicases. Heliquinomycin, a well- known antibiotic, was shown to exhibit inhibitory effects on some of the DNA replicative helicases such as DNA helicase B, RecQL4, minimal chromosome maintenance helicases 5, 6, and 7 [Sugiyama et al., 2012]. Future investigations on screening compounds similar to heliquinomycin will have the potential to provide effective RecQL4 targeting agents for cancer therapy. In our earlier study, we found that trichostatin A (a histone deacetylase inhibitor) effectively suppressed RecQL4 expression in prostate cancer cells [Su et al., 2010]. This observation opens up new possibilities for exploring different histone deacetylase inhibitors for RecQL4 targeting.

\section{Conclusions}

A PubMed search using the terms "RecQL4 helicases and Cancer" has retrieved a total of 898 publications although not all of them may directly deal with cancer aspects. Nevertheless, research focus on helicases as potential cancer therapeutic targets has been gaining momentum. Since the first report on the involvement of RecQL4 in prostate cancer [Su et al., 2010], tremendous progress has been made in unraveling the plethora of functions for RecQL4 in diverse human cancer cell types. As stated before, elevated RecQL4 expression is not a ubiquitous occurrence in cancer cells, and there may be numerous RecQL4-independent pathways for initiation and promotion of carcinogenesis. Using the available evidence, this review has attempted to highlight some of the most important hallmark activities of RecQL4 justifying its potential as a novel molecular therapeutic target for cancer. Given the importance of RecQL4 for cancer stemness, targeting RecQL4 has the additional advantage of abolishing the cancer stem cells and therefore cancer recurrence. As mentioned before [Mo et al., 2018], it remains to be determined whether elevated RecQL4 expression is a cause or consequence of the carcinogenic process. A better understanding of the oncogenic activities of RecQL4 will help in developing effective therapeutic RecQL4 targeting strategies for cancer.

\section{Acknowledgements}

The author is grateful to all the colleagues at the Radiation Emergency Assistance Center/Training Site, Oak Ridge Institute for Science and Education, Oak Ridge Associated Universities for their help and support. The author apologizes to those scientists whose important contributions could not be cited due to space limitation. 


\section{Conflict of Interest Statement}

The author has no conflict of interest to declare.

\section{Author Contributions}

A.S.B. wrote the manuscript after the conceptualization of the review, data collection, data curation. and preparation of figures.

\section{Funding Sources}

No funding was received for this study.

\section{References}

Abad E, Graifer D, Lyakhovich A. DNA damage response and resistance of cancer stem cells. Cancer Lett. 2020;474:106-17.

Abe T, Yoshimura A, Hosono Y, Tada S, Seki M, Enomoto T. The N-terminal region of RECQL4 lacking the helicase domain is both essential and sufficient for the viability of vertebrate cells. Role of the $\mathrm{N}$-terminal region of RECQL4 in cells. Biochim Biophys Acta. 2011;1813:473-9.

Aggarwal M, Sommers JA, Shoemaker RH, Brosh RM Jr. Inhibition of helicase activity by a small molecule impairs Werner syndrome helicase (WRN) function in the cellular response to DNA damage or replication stress. Proc Natl Acad Sci USA. 2011;108:1525-30.

Ajeawung NF, Nguyen TTM, Lu L, Kucharski TJ, Rousseau J, Molidperee S, et al. Mutations in ANAPC1, Encoding a Scaffold Subunit of the Anaphase-Promoting Complex, Cause Rothmund-Thomson Syndrome Type 1. Am J Hum Genet. 2019;105:625-30.

Al-Khafaji AS, Davies MP, Risk JM, Marcus MW, Koffa M, Gosney JR, et al. Aurora B expression modulates paclitaxel response in nonsmall cell lung cancer. Br J Cancer. 2017;116: 592-9.

Arai A, Chano T, Futami K, Furuichi Y, Ikebuchi $\mathrm{K}$, Inui $\mathrm{T}$, et al. RECQL1 and WRN proteins are potential therapeutic targets in head and neck squamous cell carcinoma. Cancer Res. 2011;71:4598-607.

Arora A, Abdel-Fatah TM, Agarwal D, Doherty R, Croteau DL, Moseley PM, et al. Clinicopathological and prognostic significance of RECQL5 helicase expression in breast cancers. Carcinogenesis. 2016a;37:63-71.

Arora A, Agarwal D, Abdel-Fatah TM, Lu H, Croteau DL, Moseley P, et al. RECQL4 helicase has oncogenic potential in sporadic breast cancers. J Pathol. 2016b;238:495-501.

Arora A, Parvathaneni S, Aleskandarany MA Agarwal D, Ali R, Abdel-Fatah T, et al. Clinicopathological and Functional Significance of RECQL1 Helicase in Sporadic Breast Cancers. Mol Cancer Ther. 2017;16:239-50.

Bennett RJ, Keck JL. Structure and function of RecQ DNA helicases. Crit Rev Biochem Mol Biol. 2004;39:79-97.

Birkbak NJ, Li Y, Pathania S, Greene-Colozzi A, Dreze M, Bowman-Colin C, et al. Overexpression of BLM promotes DNA damage and increased sensitivity to platinum salts in tri- ple-negative breast and serous ovarian cancers. Ann Oncol. 2018;29:903-9.

Blasco MA. Telomeres and human disease: ageing, cancer and beyond. Nat Rev Genet. 2005; 6:611-22.

Bochman ML. Roles of DNA helicases in the maintenance of genome integrity. Mol Cell Oncol. 2014;1:e963429.

Bohr VA. Rising from the RecQ-age: the role of human RecQ helicases in genome maintenance. Trends Biochem Sci. 2008;33:609-20.

Brosh RM Jr, Bohr VA. Human premature aging, DNA repair and RecQ helicases. Nucleic Acids Res. 2007;35:7527-44.

Brosh RM Jr, Matson SW. History of DNA Helicases. Genes (Basel). 2020;11:255.

Burks LM, Yin J, Plon SE. Nuclear import and retention domains in the amino terminus of RECQL4. Gene. 2007;391:26-38.

Burla R, La Torre M, Merigliano C, Vernì F, Saggio I. Genomic instability and DNA replication defects in progeroid syndromes. Nucleus. 2018;9:368-79.

Byrd AK, Raney KD. Superfamily 2 helicases. Front Biosci (Landmark Ed). 2012;17:2070-88.

Capp C, Wu J, Hsieh TS. RecQ4: the second replicative helicase? Crit Rev Biochem Mol Biol. 2010;45:233-42.

Carmena M, Wheelock M, Funabiki H, Earnshaw WC. The Chromosomal Passenger Complex (CPC): From Easy Rider to the Godfather of Mitosis. Nat Rev Mol Cell Biol. 2012;13:789803.

Chaganti RS, Schonberg S, German J. A manyfold increase in sister chromatid exchanges in Bloom's syndrome lymphocytes. Proc Natl Acad Sci USA. 1974;71:4508-12.

Chen H, Yuan K, Wang X, Wang H, Wu Q, Wu $\mathrm{X}$, et al. Overexpression of RECQL4 is associated with poor prognosis in patients with gastric cancer. Oncol Lett. 2018;16:5419-25.

Chen Y, Wang T, Huang M, Liu Q, Hu C, Wang B, et al. MAFB Promotes Cancer Stemness and Tumorigenesis in Osteosarcoma through a Sox9-Mediated Positive Feedback Loop. Cancer Res. 2020;80:2472-83.

Chi Z, Nie L, Peng Z, Yang Q, Yang K, Tao J, et al. RecQL4 cytoplasmic localization: implications in mitochondrial DNA oxidative damage repair. Int J Biochem Cell Biol. 2012;44:1942-51.

Choi YW, Bae SM, Kim YW, Lee HN, Kim YW, Park TC, et al. Gene expression profiles in squamous cell cervical carcinoma using array-based comparative genomic hybridization analysis Int J Gynecol Cancer. 2007;17:687-96.

Crevel G, Vo N, Crevel I, Hamid S, Hoa L, Miyata S, et al. Drosophila RecQ4 is directly involved in both DNA replication and the response to UV damage in S2 cells. PLoS One. 2012;7:e49505.

Croteau DL, Rossi ML, Canugovi C, Tian J, Sykora P, Ramamoorthy M, et al. RECQL4 localizes to mitochondria and preserves mitochondrial DNA integrity. Aging Cell. 2012; 11:456-66.

Croteau DL, Popuri V, Opresko PL, Bohr VA Human RecQ helicases in DNA repair, recombination, and replication. Annu Rev Biochem. 2014;83:519-52.

Cunniff C, Bassetti JA, Ellis NA. Bloom's Syndrome: Clinical Spectrum, Molecular Pathogenesis, and Cancer Predisposition. Mol Syndromol. 2017;8:4-23.

De S, Kumari J, Mudgal R, Modi P, Gupta S, Futami K, et al. RECQL4 is essential for the transport of p53 to mitochondria in normal human cells in the absence of exogenous stress. J Cell Sci. 2012;125:2509-22.

Debnath S, Sharma S. RECQ1 Helicase in Genomic Stability and Cancer. Genes (Basel). 2020;11:622.

de Voer RM, Hahn MM, Mensenkamp AR, Hoischen A, Gilissen C, Henkes A, et al. Deleterious Germline BLM Mutations and the Risk for Early-Onset Colorectal Cancer. Sci Rep. 2015;5:14060.

Dhar S, Datta A, Brosh RM Jr. DNA helicases and their roles in cancer. DNA Repair (Amst). 2020;96:102994.

Doherty KM, Sharma S, Uzdilla LA, Wilson TM, Cui S, Vindigni A, et al. RECQ1 helicase interacts with human mismatch repair factors that regulate genetic recombination. J Biol Chem. 2005;280:28085-94.

Duan Y, Fang H. RecQL4 regulates autophagy and apoptosis in U2OS cells. Biochem Cell Biol. 2016;94:551-9.

Ellis NA, Groden J, Ye TZ, Straughen J, Lennon DJ, Ciocci S, et al. The Bloom's syndrome gene product is homologous to RecQ helicases. Cell. 1995;83:655-66.

Fan W, Luo J. RecQ4 facilitates UV light-induced DNA damage repair through interaction with nucleotide excision repair factor xeroderma pigmentosum group A (XPA). J Biol Chem. 2008;283:29037-44. 
Fang H, Nie L, Chi Z, Liu J, Guo D, Lu X, et al. RecQL4 helicase amplification is involved in human breast tumorigenesis. PLoS One. 2013;8:e69600.

Fang H, Niu K, Mo D, Zhu Y, Tan Q, Wei D, et al. RecQL4-Aurora B kinase axis is essential for cellular proliferation, cell cycle progression, and mitotic integrity. Oncogenesis. 2018;7:68.

Feng D, Tu Z, Wu W, Liang C. Inhibiting the expression of DNA replication-initiation proteins induces apoptosis in human cancer cells. Cancer Res. 2003;63:7356-64.

Futami K, Furuichi Y. RECQL1 and WRN DNA repair helicases: potential therapeutic targets and proliferative markers against cancers. Front Genet. 2014;5:441.

Garige M, Sharma S. Cellular deficiency of Werner syndrome protein or RECQ1 promotes genotoxic potential of hydroquinone and benzo[a]pyrene exposure. Int J Toxicol. 2014; 33:373-81.

Gebhart E, Bauer R, Raub U, Schinzel M, Ruprecht KW, Jonas JB. Spontaneous and induced chromosomal instability in Werner syndrome. Hum Genet. 1988;80:135-9.

Ghosh AK, Rossi ML, Singh DK, Dunn C, Ramamoorthy M, Croteau DL, et al. RECQL4, the protein mutated in Rothmund-Thomson syndrome, functions in telomere maintenance. J Biol Chem. 2012;287:196-209.

Gonzalez-Loyola A, Fernandez-Miranda G, Trakala M, Partida D, Samejima K, Ogawa H, et al. Aurora B Overexpression Causes Aneuploidy and p21Cip1 Repression during Tumor Development. Mol Cell Biol. 2015;35: 3566-78.

González-Magaña A, Blanco FJ. Human PCNA Structure, Function and Interactions. Biomolecules. 2020;10:570.

Goto M, Imamura O, Kuromitsu J, Matsumoto T, Yamabe Y, Tokutake Y, et al. Analysis of helicase gene mutations in Japanese Werner's syndrome patients. Hum Genet. 1997;99: 191-3.

Griffin CA, Morsberger L, Hawkins AL, Haddadin M, Patel A, Ried T, et al. Molecular cytogenetic characterization of pancreas cancer cell lines reveals high complexity chromosomal alterations. Cytogenet Genome Res. 2007;118:148-56.

Guo L, Li Y, Zhao C, Peng J, Song K, Chen L, et al. RECQL4, Negatively Regulated by miR10a-5p, Facilitates Cell Proliferation and Invasion via MAFB in Ovarian Cancer. Front Oncol. 2020;10:524128.

Gupta R, Brosh RM Jr. DNA repair helicases as targets for anti-cancer therapy. Curr Med Chem. 2007;14:503-17.

Gupta S, De S, Srivastava V, Hussain M, Kumari J, Muniyappa K, et al. RECQL4 and p53 potentiate the activity of polymerase $\gamma$ and maintain the integrity of the human mitochondrial genome. Carcinogenesis. 2014;35: $34-45$.

Hanada K, Hickson ID. Molecular genetics of RecQ helicase disorders. Cell Mol Life Sci. 2007;64:2306-22.
Hanahan D, Weinberg RA. The hallmarks of cancer. Cell. 2000;100:57-70.

Hsieh AL, Walton ZE, Altman BJ, Stine ZE, Dang CV. MYC and metabolism on the path to cancer. Semin Cell Dev Biol. 2015;43:11-21.

Huang D, Huang Y, Huang Z, Weng J, Zhang S, $\mathrm{Gu}$ W. Relation of AURKB over-expression to low survival rate in BCRA and reversinemodulated aurora B kinase in breast cancer cell lines. Cancer Cell Int. 2019;19:166.

Huson SM, Rodgers CS, Hall CM, Winter RM. The Baller-Gerold syndrome: phenotypic and cytogenetic overlap with Roberts syndrome. J Med Genet. 1990;27:371-5.

Im JS, Ki SH, Farina A, Jung DS, Hurwitz J, Lee JK. Assembly of the Cdc45-Mcm2-7-GINS complex in human cells requires the Ctf4/ And-1, RecQL4, and Mcm10 proteins. Proc Natl Acad Sci USA. 2009;106:15628-32.

Im JS, Park SY, Cho WH, Bae SH, Hurwitz J, Lee $\mathrm{JK}$. RecQL4 is required for the association of $\mathrm{Mcm} 10$ and Ctf4 with replication origins in human cells. Cell Cycle. 2015;14:1001-9.

Imamura O, Fujita K, Itoh C, Takeda S, Furuichi $\mathrm{Y}$, Matsumoto T. Werner and Bloom helicases are involved in DNA repair in a complementary fashion. Oncogene. 2002;21:954-63.

Jain CK, Mukhopadhyay S, Ganguly A. RecQ Family Helicases in Replication Fork Remodeling and Repair: Opening New Avenues towards the Identification of Potential Targets for Cancer Chemotherapy. Anticancer Agents Med Chem. 2020;20:1311-26.

Jin W, Liu H, Zhang Y, Otta SK, Plon SE, Wang LL. Sensitivity of RECQL4-deficient fibroblasts from Rothmund-Thomson syndrome patients to genotoxic agents. Hum Genet. 2008; 123:643-53.

Kawabe T, Tsuyama N, Kitao S, Nishikawa K, Shimamoto A, Shiratori M, et al. Differential regulation of human RecQ family helicases in cell transformation and cell cycle. Oncogene. 2000;19:4764-72.

Killoran MP, Keck JL. Sit down, relax and unwind: structural insights into RecQ helicase mechanisms. Nucleic Acids Res. 2006;34: 4098-105.

Kitao S, Ohsugi I, Ichikawa K, Goto M, Furuichi Y, Shimamoto A. Cloning of two new human helicase genes of the RecQ family: biological significance of multiple species in higher eukaryotes. Genomics. 1998;54:443-52.

Kitao S, Lindor NM, Shiratori M, Furuichi Y, Shimamoto A. Rothmund-Thomson syndrome responsible gene, RECQL4: genomic structure and products. Genomics. 1999;61:26876.

Kliszczak M, Sedlackova H, Pitchai GP, Streicher WW, Krejci L, Hickson ID. Interaction of RECQ4 and MCM10 is important for efficient DNA replication origin firing in human cells. Oncotarget. 2015;6:40464-79.

Knuutila S, Björkqvist AM, Autio K, Tarkkanen $\mathrm{M}$, Wolf M, Monni O, et al. DNA copy number amplifications in human neoplasms: review of comparative genomic hybridization studies. Am J Pathol. 1998;152:1107-23.
Kohzaki M, Ootsuyama A, Sun L, Moritake T, Okazaki R. Human RECQL4 represses the RAD52-mediated single-strand annealing pathway after ionizing radiation or cisplatin treatment. Int J Cancer. 2020;146:3098-113.

Krepinsky AB, Heddle JA, German J. Sensitivity of Bloom's syndrome lymphocytes to ethyl methanesulfonate. Hum Genet. 1979;50:151-6.

Król SK, Kaczmarczyk A, Wojnicki K, Wojtas B, Gielniewski B, Grajkowska W, et al. Aberrantly Expressed RECQL4 Helicase Supports Proliferation and Drug Resistance of Human Glioma Cells and Glioma Stem Cells. Cancers (Basel). 2020;12:2919.

Kumata Y, Tada S, Yamanada Y, Tsuyama T, Kobayashi T, Dong YP, et al. Possible involvement of RecQL4 in the repair of doublestrand DNA breaks in Xenopus egg extracts. Biochim Biophys Acta. 2007;1773:556-64.

Kurihara T, Inoue M, Tatsumi K. Hypersensitivity of Bloom's syndrome fibroblasts to N-ethylN-nitrosourea. Mutat Res. 1987;184:147-51.

Larizza L, Roversi G, Volpi L. Rothmund-Thomson syndrome. Orphanet J Rare Dis. 2010;5:2.

Larsen NB, Hickson ID. RecQ Helicases: Conserved Guardians of Genomic Integrity. Adv Exp Med Biol. 2013;767:161-84.

Lauper JM, Krause A, Vaughan TL, Monnat RJ Jr. Spectrum and risk of neoplasia in Werner syndrome: a systematic review. PLoS One. 2013;8:e59709.

Lindor NM, Devries EM, Michels VV, Schad CR, Jalal SM, Donovan KM, et al. RothmundThomson syndrome in siblings: evidence for acquired in vivo mosaicism. Clin Genet. 1996; 49:124-9.

Lindor NM, Furuichi Y, Kitao S, Shimamoto A, Arndt C, Jalal S. Rothmund-Thomson syndrome due to RECQ4 helicase mutations: report and clinical and molecular comparisons with Bloom syndrome and Werner syndrome. Am J Med Genet. 2000;90:223-8.

Lu H, Fang EF, Sykora P, Kulikowicz T, Zhang Y, Becker KG, et al. Senescence induced by RECQL4 dysfunction contributes to RothmundThomson syndrome features in mice. Cell Death Dis. 2014;5:e1226.

Lu H, Shamanna RA, Keijzers G, Anand R, Rasmussen LJ, Cejka P, et al. RECQL4 Promotes DNA End Resection in Repair of DNA Double-Strand Breaks. Cell Rep. 2016;16:161-73.

Lu L, Jin W, Liu H, Wang LL. RECQ DNA helicases and osteosarcoma. Adv Exp Med Biol. 2014;804:129-45.

Lu L, Harutyunyan K, Jin W, Wu J, Yang T, Chen $Y$, et al. RECQL4 Regulates p53 Function In Vivo During Skeletogenesis. J Bone Miner Res. 2015;30:1077-89.

$\mathrm{Lu}$ L, Jin W, Wang LL. RECQ DNA Helicases and Osteosarcoma. Adv Exp Med Biol. 2020;1258: 37-54.

Machlowska J, Kapusta P, Baj J, Morsink FHM, Wołkow P, Maciejewski R, et al. HighThroughput Sequencing of Gastric Cancer Patients: Unravelling Genetic Predispositions Towards an Early-Onset Subtype. Cancers (Basel). 2020;12:1981. 
Maciaszek JL, Oak N, Chen W, Hamilton KV, McGee RB, Nuccio R, et al. Enrichment of heterozygous germline RECQL4 loss-offunction variants in pediatric osteosarcoma. Cold Spring Harb Mol Case Stud. 2019;5: a004218.

Maire G, Yoshimoto M, Chilton-MacNeill S, Thorner PS, Zielenska M, Squire JA. Recurrent RECQL4 imbalance and increased gene expression levels are associated with structural chromosomal instability in sporadic osteosarcoma. Neoplasia. 2009;11:260-8, 3p following 268 .

Malkas LH, Herbert BS, Abdel-Aziz W, Dobrolecki LE, Liu Y, Agarwal B, et al. A cancerassociated PCNA expressed in breast cancer has implications as a potential biomarker. Proc Natl Acad Sci USA. 2006;103:19472-7.

Mao FJ, Sidorova JM, Lauper JM, Emond MJ, Monnat RJ. The human WRN and BLM RecQ helicases differentially regulate cell proliferation and survival after chemotherapeutic DNA damage. Cancer Res. 2010;70: 6548-55.

Marino F, Vindigni A, Onesti S. Bioinformatic analysis of RecQ4 helicases reveals the presence of a RQC domain and a Zn knuckle. Biophys Chem. 2013;177-178:34-9.

Marino F, Mojumdar A, Zucchelli C, Bhardwaj A, Buratti E, Vindigni A, et al. Structural and biochemical characterization of an RNA/ DNA binding motif in the N-terminal domain of RecQ4 helicases. Sci Rep. 2016;6: 21501.

Maruyama S, Ohkita N, Nakayama M, Akaboshi E, Shibata T, Funakoshi E, et al. RecQ5 interacts with Rad51 and is involved in resistance of Drosophila to cisplatin treatment. Biol Pharm Bull. 2012;35:2017-22.

Masai H. RecQL4: a helicase linking formation and maintenance of a replication fork. J Biochem. 2011;149:629-31.

Matsuno K, Kumano M, Kubota Y, Hashimoto Y, Takisawa $\mathrm{H}$. The $\mathrm{N}$-terminal noncatalytic region of Xenopus RecQ4 is required for chromatin binding of DNA polymerase alpha in the initiation of DNA replication. Mol Cell Biol. 2006;26:4843-52.

Maugeri-Saccà M, Di Martino S, De Maria R. Biological and clinical implications of cancer stem cells in primary brain tumors. Front Oncol. 2013;3:6.

Mo D, Fang H, Niu K, Liu J, Wu M, Li S, et al. Human Helicase RECQL4 Drives Cisplatin Resistance in Gastric Cancer by Activating an AKT-YB1-MDR1 Signaling Pathway. Cancer Res. 2016;76:3057-66.

Mo D, Zhao Y, Balajee AS. Human RecQL4 helicase plays multifaceted roles in the genomic stability of normal and cancer cells. Cancer Lett. 2018;413:1-10.

Mojumdar A. Mutations in conserved functional domains of human RecQ helicases are associated with diseases and cancer: A review. Biophys Chem. 2020;265:106433.

Moles R, Bai XT, Chaib-Mezrag H, Nicot C. WRN-targeted therapy using inhibitors NSC
19630 and NSC 617145 induce apoptosis in HTLV-1-transformed adult T-cell leukemia cells. J Hematol Oncol. 2016;9:121.

Monnat RJ Jr, Hackmann AF, Chiaverotti TA. Nucleotide sequence analysis of human hypoxanthine phosphoribosyltransferase (HPRT) gene deletions. Genomics. 1992;13:777-87.

Moser MJ, Oshima J, Monnat RJ Jr. WRN mutations in Werner syndrome. Hum Mutat. 1999; 13:271-9.

Motegi S, Uchiyama A, Yamada K, Ogino S, Yokoyama Y, Perera B, et al. Increased susceptibility to oxidative stress- and ultraviolet Ainduced apoptosis in fibroblasts in atypical progeroid syndrome/atypical Werner syndrome with LMNA mutation. Exp Dermatol. 2016;25(Suppl 3):20-7.

Nguyen GH, Dexheimer TS, Rosenthal AS, Chu WK, Singh DK, Mosedale G, et al. A small molecule inhibitor of the BLM helicase modulates chromosome stability in human cells. Chem Biol. 2013;20:55-62.

Nickens DG, Rogers CM, Bochman ML. The Saccharomyces cerevisiae Hrq1 and Pif1 DNA helicases synergistically modulate telomerase activity in vitro. J Biol Chem. 2018;293: 14481-96.

Nicotera TM. Molecular and biochemical aspects of Bloom's syndrome. Cancer Genet Cytogenet. 1991;53:1-13.

Nicotera TM. Free radical mechanisms for chromosomal instability in Bloom's syndrome. Adv Exp Med Biol. 1994;366:29-41.

Nicotera TM, Notaro J, Notaro S, Schumer J, Sandberg AA. Elevated superoxide dismutase in Bloom's syndrome: a genetic condition of oxidative stress. Cancer Res. 1989;49:523943.

Ogburn CE, Oshima J, Poot M, Chen R, Hunt KE, Gollahon KA, et al. An apoptosis-inducing genotoxin differentiates heterozygotic carriers for Werner helicase mutations from wildtype and homozygous mutants. Hum Genet. 1997; 101:121-5.

Ohishi T, Muramatsu Y, Yoshida H, Seimiya H. TRF1 ensures the centromeric function of Aurora-B and proper chromosome segregation. Mol Cell Biol. 2014;34:2464-78.

Ohlenschläger $\mathrm{O}$, Kuhnert A, Schneider A, Haumann S, Bellstedt P, Keller H, et al. The $\mathrm{N}$-terminus of the human RecQL4 helicase is a homeodomain-like DNA interaction motif. Nucleic Acids Res. 2012;40:8309-24.

Opresko PL, von Kobbe C, Laine JP, Harrigan J, Hickson ID, Bohr VA. Telomere-binding protein TRF2 binds to and stimulates the Werner and Bloom syndrome helicases. J Biol Chem. 2002;277:41110-9.

Oshima J, Yu CE, Piussan C, Klein G, Jabkowski $\mathrm{J}$, Balci S, et al. Homozygous and compound heterozygous mutations at the Werner syndrome locus. Hum Mol Genet. 1996;5:190913.

Oshima J, Sidorova JM, Monnat RJ Jr. Werner syndrome: Clinical features, pathogenesis and potential therapeutic interventions. Ageing Res Rev. 2017;33:105-14.
Paliwal S, Kanagaraj R, Sturzenegger A, Burdova K, Janscak P. Human RECQ5 helicase promotes repair of DNA double-strand breaks by synthesis-dependent strand annealing. $\mathrm{Nu}$ cleic Acids Res. 2014;42:2380-90.

Pannone G, Hindi SA, Santoro A, Sanguedolce F, Rubini C, Cincione RI, et al. Aurora B expression as a prognostic indicator and possible therapeutic target in oral squamous cell carcinoma. Int J Immunopathol Pharmacol. 2011; 24:79-88

Parada LA, Hallén M, Tranberg KG, Hägerstrand I, Bondeson L, Mitelman F, et al. Frequent rearrangements of chromosomes 1, 7, and 8 in primary liver cancer. Genes Chromosomes Cancer. 1998;23:26-35.

Parvathaneni S, Stortchevoi A, Sommers JA, Brosh RM Jr, Sharma S. Human RECQ1 interacts with Ku70/80 and modulates DNA end-joining of double-strand breaks. PLoS One. 2013; 8:e62481.

Patil AV, Hsieh TS. Ribosomal Protein S3 Negatively Regulates Unwinding Activity of RecQlike Helicase 4 through Their Physical Interaction. J Biol Chem. 2017;292:4313-25.

Poot M, Gollahon KA, Rabinovitch PS. Werner syndrome lymphoblastoid cells are sensitive to camptothecin-induced apoptosis in Sphase. Hum Genet. 1999;104:10-4.

Poot M, Yom JS, Whang SH, Kato JT, Gollahon KA, Rabinovitch PS. Werner syndrome cells are sensitive to DNA cross-linking drugs. FASEB J. 2001;15:1224-6.

Poot M, Gollahon KA, Emond MJ, Silber JR, Rabinovitch PS. Werner syndrome diploid fibroblasts are sensitive to 4-nitroquinoline- $\mathrm{N}$ oxide and 8-methoxypsoralen: implications for the disease phenotype. FASEB J. 2002;16: 757-8.

Puranam KL, Blackshear PJ. Cloning and characterization of RECQL, a potential human homologue of the Escherichia coli DNA helicase RecQ. J Biol Chem. 1994;269:29838-45.

Qian J, Jenkins RB, Bostwick DG. Determination of gene and chromosome dosage in prostatic intraepithelial neoplasia and carcinoma. Anal Quant Cytol Histol. 1998;20:373-80.

Saglam O, Shah V, Worsham MJ. Molecular differentiation of early and late stage laryngeal squamous cell carcinoma: an exploratory analysis. Diagn Mol Pathol. 2007;16:218-21.

Salahshourifar I, Vincent-Chong VK, Kallarakkal TG, Zain RB. Genomic DNA copy number alterations from precursor oral lesions to oral squamous cell carcinoma. Oral Oncol. 2014; 50:404-12.

Salk D, Au K, Hoehn H, Martin GM. Cytogenetics of Werner's syndrome cultured skin fibroblasts: variegated translocation mosaicism. Cytogenet Cell Genet. 1981;30:92-107.

Sami F, Lu X, Parvathaneni S, Roy R, Gary RK, Sharma S. RECQ1 interacts with FEN-1 and promotes binding of $\mathrm{FEN}-1$ to telomeric chromatin. Biochem J. 2015;468:227-44.

Sana M, Malik HJ. Current and emerging breast cancer biomarkers. J Cancer Res Ther. 2015; 11:508-13. 
Sangrithi MN, Bernal JA, Madine M, Philpott A, Lee J, Dunphy WG, et al. Initiation of DNA replication requires the RECQL4 protein mutated in Rothmund-Thomson syndrome. Cell. 2005;121:887-98.

Schmit M, Bielinsky AK. Congenital Diseases of DNA Replication: Clinical Phenotypes and Molecular Mechanisms. Int J Mol Sci. 2021; 22:911.

Schurman SH, Hedayati M, Wang Z, Singh DK, Speina E, Zhang Y, et al. Direct and indirect roles of RECQL4 in modulating base excision repair capacity. Hum Mol Genet. 2009;18: 3470-83.

Schwendener S, Raynard S, Paliwal S, Cheng A, Kanagaraj R, Shevelev I, et al. Physical interaction of RECQ5 helicase with RAD51 facilitates its anti-recombinase activity. J Biol Chem. 2010;285:15739-45.

Sekelsky JJ, Brodsky MH, Rubin GM, Hawley RS. Drosophila and human RecQ5 exist in different isoforms generated by alternative splicing. Nucleic Acids Res. 1999;27:3762-9.

Sengupta S, Shimamoto A, Koshiji M, Pedeux R, Rusin M, Spillare EA, et al. Tumor suppressor p53 represses transcription of RECQ4 helicase. Oncogene. 2005;24:1738-48.

Sfeir A, Kosiyatrakul ST, Hockemeyer D, MacRae SL, Karlseder J, Schildkraut CL, et al. Mammalian telomeres resemble fragile sites and require TRF1 for efficient replication. Cell. 2009; 138:90-103.

Shamanna RA, Singh DK, Lu H, Mirey G, Keijzers G, Salles B, et al. RECQ helicase RECQL4 participates in non-homologous end joining and interacts with the $\mathrm{Ku}$ complex. Carcinogenesis. 2014;35:2415-24.

Sharma S, Brosh RM Jr. Human RECQ1 is a DNA damage responsive protein required for genotoxic stress resistance and suppression of sister chromatid exchanges. PLoS One. 2007;2 e1297.

Sharma S, Doherty KM, Brosh RM Jr. DNA helicases as targets for anti-cancer drugs. Curr Med Chem Anticancer Agents. 2005;5:18399.

Sharma S, Doherty KM, Brosh RM Jr. Mechanisms of RecQ helicases in pathways of DNA metabolism and maintenance of genomic stability. Biochem J. 2006;398:319-37.

Sharma S, Stumpo DJ, Balajee AS, Bock CB, Lansdorp PM, Brosh RM Jr, et al. RECQL, a member of the RecQ family of DNA helicases, suppresses chromosomal instability. Mol Cell Biol. 2007;27:1784-94.

Sharma S, Phatak P, Stortchevoi A, Jasin M Larocque JR. RECQ1 plays a distinct role in cellular response to oxidative DNA damage. DNA Repair (Amst). 2012;11:537-49.

Shen F, Kirmani KZ, Xiao Z, Thirlby BH, Hickey RJ, Malkas LH. Nuclear protein isoforms: implications for cancer diagnosis and therapy. J Cell Biochem. 2011;112:756-60.

Shields CL, Dalvin LA, Vichitvejpaisal P, Mazloumi M, Ganguly A, Shields JA. Prognostication of uveal melanoma is simple and highly predictive using The Cancer Genome Atlas
(TCGA) classification: A review. Indian J Ophthalmol. 2019;67:1959-63.

Shimamoto A, Nishikawa K, Kitao S, Furuichi Y. Human RecQ5beta, a large isomer of RecQ5 DNA helicase, localizes in the nucleoplasm and interacts with topoisomerases 3alpha and 3beta. Nucleic Acids Res. 2000;28:1647-55.

Shin G, Jeong D, Kim H, Im JS, Lee JK. RecQL4 tethering on the pre-replicative complex induces unscheduled origin activation and replication stress in human cells. J Biol Chem. 2019;294:16255-65.

Shiraishi Y. Bloom syndrome B-lymphoblastoid cells are hypersensitive towards carcinogen and tumor promoter-induced chromosomal alterations and growth in agar. EMBO J. 1985; 4:2553-60.

Shiraishi Y, Sandberg AA. Effects of chemicals on the frequency of sister chromatid exchanges and chromosome aberrations in normal and Bloom's syndrome lymphocytes. Cytobios. 1979a;26:91-108.

Shiraishi Y, Sandberg AA. Effects of various chemical agents on sister chromatid exchanges, chromosome aberrations, and DNA repair in normal and abnormal human lymphoid cell lines. J Natl Cancer Inst. 1979b;62:27-35.

Siitonen HA, Kopra O, Kaariainen H, Haravuori $\mathrm{H}$, Winter RM, Saamanen AM, et al. Molecular defect of RAPADILINO syndrome expands the phenotype spectrum of RECQL diseases. Hum Mol Genet. 2003;12:2837-44

Simon T, Kohlhase J, Wilhelm C, Kochanek M, De Carolis B, Berthold F. Multiple malignant diseases in a patient with Rothmund-Thomson syndrome with RECQL4 mutations: Case report and literature review. Am J Med Genet A. 2010;152A:1575-9.

Singh DK, Karmakar P, Aamann M, Schurman $\mathrm{SH}$, May A, Croteau DL, et al. The involvement of human RECQL4 in DNA doublestrand break repair. Aging Cell. 2010;9:35871.

Skvortsova I, Debbage P, Kumar V, Skvortsov S. Radiation resistance: Cancer stem cells (CSCs) and their enigmatic pro-survival signaling. Semin Cancer Biol. 2015;35:39-44.

Slimane SN, Marcel V, Fenouil T, Catez F, Saurin JC, Bouvet P, et al. Ribosome Biogenesis Alterations in Colorectal Cancer. Cells. 2020;9: 2361.

Smeets MF, DeLuca E, Wall M, Quach JM, Chalk AM, Deans AJ, et al. The Rothmund-Thomson syndrome helicase RECQL4 is essential for hematopoiesis. J Clin Invest. 2014;124: 3551-65.

Stine ZE, Walton ZE, Altman BJ, Hsieh AL, Dang CV. MYC, Metabolism, and Cancer. Cancer Discov. 2015;5:1024-39.

Su Y, Meador JA, Calaf GM, Proietti De-Santis L, Zhao Y, Bohr VA, et al. Human RecQL4 helicase plays critical roles in prostate carcinogenesis. Cancer Res. 2010;70:9207-17.

Sugiyama T, Chino M, Tsurimoto T, Nozaki N, Ishimi Y. Interaction of heliquinomycin with single-stranded DNA inhibits MCM4/6/7 helicase. J Biochem. 2012;151:129-37.
Tanaka S, Umemori T, Hirai K, Muramatsu S, Kamimura Y, Araki H. CDK-dependent phosphorylation of Sld2 and Sld3 initiates DNA replication in budding yeast. Nature. 2007; 445:328-32.

Thangavel S, Mendoza-Maldonado R, Tissino E Sidorova JM, Yin J, Wang W, et al. Human RECQ1 and RECQ4 helicases play distinct roles in DNA replication initiation. Mol Cell Biol. 2010;30:1382-96.

Tseng BS, Tan L, Kapoor TM, Funabiki H. Dual Detection of Chromosomes and Microtubules by the Chromosomal Passenger Complex Drives Spindle Assembly. Dev Cell. 2010; 18:903-12.

Turner KJ, Vasu V, Griffin DK. Telomere Biology and Human Phenotype. Cells. 2019;8:73.

Vader G, Maia AF, Lens SM. The chromosomal passenger complex and the spindle assembly checkpoint: kinetochore-microtubule error correction and beyond. Cell Div. 2008;3:10.

VanGenderen C, Harkness TAA, Arnason TG. The role of Anaphase Promoting Complex activation, inhibition and substrates in cancer development and progression. Aging (Albany NY). 2020;12:15818-55.

Van Maldergem L, Siitonen HA, Jalkh N, Chouery E, De Roy M, Delague V, et al. Revisiting the craniosynostosis-radial ray hypoplasia association: Baller-Gerold syndrome caused by mutations in the RECQL4 gene. J Med Genet. 2006;43:148-52.

Victorelli S, Passos JF. Telomeres and Cell Senescence - Size Matters Not. EBioMedicine. 2017;21:14-20.

Von Kobbe C, May A, Grandori C, Bohr VA. Werner syndrome cells escape hydrogen peroxide-induced cell proliferation arrest. FASEB J. 2004;18:1970-2.

Votino C, Laudanna C, Parcesepe P, Giordano G, Remo A, Manfrin E, et al. Aberrant BLM cytoplasmic expression associates with DNA damage stress and hypersensitivity to DNAdamaging agents in colorectal cancer. J Gastroenterol. 2017;52:327-40.

Wang X, Hickey RJ, Malkas LH, Koch MO, Li L, Zhang S, et al. Elevated expression of cancerassociated proliferating cell nuclear antigen in high-grade prostatic intraepithelial neoplasia and prostate cancer. Prostate. 2011;71:74854.

Werner SR, Prahalad AK, Yang J, Hock JM. RECQL4-deficient cells are hypersensitive to oxidative stress/damage: Insights for osteosarcoma prevalence and heterogeneity in Rothmund-Thomson syndrome. Biochem Biophys Res Commun. 2006;345:403-9.

Woo LL, Futami K, Shimamoto A, Furuichi Y, Frank KM. The Rothmund-Thomson gene product RECQL4 localizes to the nucleolus in response to oxidative stress. Exp Cell Res. 2006;312:3443-57.

Wu J, Capp C, Feng L, Hsieh TS. Drosophila homologue of the Rothmund-Thomson syndrome gene: essential function in DNA replication during development. Dev Biol. 2008; 323:130-42. 
Wu J, Zhi L, Dai X, Cai Q, Ma W. Decreased RECQL5 correlated with disease progression of osteosarcoma. Biochem Biophys Res Commun. 2015;467:617-22.

Xi XG. Helicases as antiviral and anticancer drug targets. Curr Med Chem. 2007;14:883-915.

Xia HW, Zhang ZQ, Yuan J, Niu QL. Human RECQL5 promotes metastasis and resistance to cisplatin in non-small cell lung cancer. Life Sci. 2021;265:118768.

Yin J, Kwon YT, Varshavsky A, Wang W. RECQL4, mutated in the Rothmund-Thomson and RAPADILINO syndromes, interacts with ubiquitin ligases UBR1 and UBR2 of the Nend rule pathway. Hum Mol Genet. 2004;13: 2421-30.
Ying KL, Oizumi J, Curry CJ. Rothmund-Thomson syndrome associated with trisomy $8 \mathrm{mo}-$ saicism. J Med Genet. 1990;27:258-60.

Yokoyama H, Moreno-Andres D, Astrinidis SA, Hao Y, Weberruss M, Schellhaus AK, et al. Chromosome alignment maintenance requires the MAP RECQL4, mutated in the Rothmund-Thomson syndrome. Life Sci Alliance. 2019;2:e201800120.

Yong ZW, Zaini ZM, Kallarakkal TG, Karen-Ng LP, Rahman ZA, Ismail SM, et al. Genetic alterations of chromosome 8 genes in oral cancer. Sci Rep. 2014;4:6073.

Yu CE, Oshima J, Fu YH, Wijsman EM, Hisama F, Alisch R, et al. Positional cloning of the Werner's syndrome gene. Science. 1996;272: 258-62.
Zhang Y, Jiang C, Li H, Lv F, Li X, Qian X, et al. Elevated Aurora B expression contributes to chemoresistance and poor prognosis in breast cancer. Int J Clin Exp Pathol. 2015;8:751-7.

Zheng L, Kanagaraj R, Mihaljevic B, Schwendener S, Sartori AA, Gerrits B, et al. MRE11 complex links RECQ5 helicase to sites of DNA damage. Nucleic Acids Res. 2009;37:2645-57.

Zhu X, Chen H, Yang Y, Xu C, Zhou J, Zhou J, et al. Distinct prognosis of mRNA expression of the five RecQ DNA-helicase family members - RECQL, BLM, WRN, RECQL4, and RECQL5 - in patients with breast cancer. Cancer Manag Res. 2018;10:6649-68. 